\title{
Comprehensive Insights Into the Occurrence, Source, Distribution and Risk Assessment of Polycyclic Aromatic Hydrocarbons in a Large Drinking Reservoir System
}

\section{Xiangyang $\mathrm{Xu}$}

Hefei University of Technology School of Resources and Environmental Engineering

Kangping Cui

Hefei University of Technology School of Resources and Environmental Engineering

Yihan Chen ( $\nabla$ yhchen@hfut.edu.cn )

Hefei University of Technology School of Resources and Environmental Engineering

\section{Xing Chen}

Hefei University of Technology Institute of Industry \& Equipment Technology

\section{Zhi Guo}

Hefei University of Technology School of Resources and Environmental Engineering

Hongjie Chen

National University of Singapore Environmental Research Institute

\section{Guangwei Deng}

Hefei University of Technology School of Management

\section{Yiliang He}

Shanghai Jiaotong University School of Environmental Science and Engineering

\section{Research Article}

Keywords: Polycyclic aromatic hydrocarbons, Fengshuba Reservior, Occurrence, Risk assessment, Indicator

Posted Date: June 4th, 2021

DOl: https://doi.org/10.21203/rs.3.rs-542749/v1

License: (1) This work is licensed under a Creative Commons Attribution 4.0 International License. Read Full License 
Version of Record: A version of this preprint was published at Environmental Science and Pollution Research on August 27th, 2021. See the published version at https://doi.org/10.1007/s11356-021-161420 . 


\section{Comprehensive insights into the occurrence, source, distribution and risk}

assessment of polycyclic aromatic hydrocarbons in a large drinking reservoir

\section{system}

Xiangyang $\mathrm{Xu}{ }^{\text {a }}$, Kangping Cui a , Yihan Chen ${ }^{\text {a, }}{ }^{*}$, Xing Chen ${ }^{\mathrm{c}}$, Zhi Guo ${ }^{\mathrm{a}}$, Hongjie

Chen ${ }^{\mathrm{d}}$, Guangwei Deng ${ }^{\mathrm{e}}$, Yiliang He $\mathrm{b}^{\text {* }}$

a School of Resources and Environmental Engineering, Hefei University of Technology, Hefei 230009, China

b School of Environmental Science and Engineering, Shanghai Jiao Tong University, Shanghai 200240, China

c Key Lab of Aerospace Structural Parts Forming Technology and Equipment of Anhui Province, Institute of Industry and Equipment Technology, Hefei University of Technology, Hefei, 230009, China

d NUS Environmental Research Institute, National University of Singapore, 5A

Engineering Drive 1, \#02-01, Singapore 117411, Singapore

e School of Management, Hefei University of Technology, Hefei 230009, China

Correspondence: Yihan Chen, PhD, School of Resources and Environmental Engineering, Hefei University of Technology, 193 Tunxi Road, Hefei 230009, China. Email: yhchen@hfut.edu.cn; Yiliang He, PhD, School of Environmental Science \& Engineering, Shanghai Jiao Tong University, 800 Dongchuan Road, Shanghai 200240, China. Tel. 86-21-54744008. Email: ylhe@sjtu.edu.cn 


\section{Abstract}

The resource, environment, and ecological value of drinking reservoirs have received widespread concerns due to the pollution of persistent organic pollutants such as polycyclic aromatic hydrocarbons (PAHs). Therefore, we comprehensively studied the occurrence, source, distribution and risk assessment of representative PAHs in Fengshuba Reservoir (FSBR) (large drinking reservoir, China). The total concentrations of 16 USEPA PAHs in the water phase, porewater phase, sediment phase and soil phase were in ranges of 109.72-393.19 $\mathrm{ng} / \mathrm{L}, 5.75-35.15 \mu \mathrm{g} / \mathrm{L}, 364.4-743.71 \mu \mathrm{g} / \mathrm{kg}$ and 367.81-639.89 $\mu \mathrm{g} / \mathrm{kg}$, respectively. The naphthalene (Nap) was the dominant PAHs in the water phase, while it was Nap and phenanthrene (Phe) in porewater, sediment and soil phase. The main sources of PAHs in FSBR were biomass combustion. Redundancy analysis indicated that, the $\mathrm{NTU}, \mathrm{NO}_{2}{ }^{-}, \mathrm{NH}_{4}{ }^{+}, \mathrm{Chl}-\alpha$ and IC were the dominant factor influencing the PAHs distribution in water phase and the PAHs in sediment phase was affected by $\mathrm{T}$ and $\mathrm{NO}_{3}{ }^{-}$. Pseudo-partitioning coefficients indicated that the PAHs in the porewater phase was more likely to migrate to the sediment phase. Risk assessment indicated that the PAHs both in the water and sediment phases were generally in a Lowrisk state, while the PAHs in the soil phase were in a Moderate-risk state and the Nap was in a High-risk state, and exposure to the PAHs in FSBR through drinking and skin exposure had little impact on consumers' health. In summary, Nap could be used as a key indicator to evaluate the existence and potential risk of PAHs in FSBR.

Key Word: Polycyclic aromatic hydrocarbons; Fengshuba Reservior; Occurrence; Risk assessment; Indicator. 


\section{Introduction}

Polycyclic aromatic hydrocarbons (PAHs) are persistent pollutants that contain two or more fused rings (Cao et al., 2017, El-Saeid et al., 2015), and are widely present in various environmental media (Han et al., 2019, Saeedi et al., 2012, Mojiri et al., 2019, Bianco et al., 2020). Due to their carcinogenicity, teratogenicity and mutagenicity and the ability to migrate over long distances (He et al., 2020, Tobiszewski and Namiesnik, 2012), PAHs has attracted much attention for the harm to ecological environment and human health (Lu et al., 2019). The United States Environmental Protection Agency (USEPA) lists 16 kinds of PAHs as priority pollutants (Keith and Telliard, 1979), and the International Agency for Research Cancer (IARC) lists many PAHs such as benzo (a) pyrene (Bap) as carcinogenic pollutants. The sources of PAHs include natural processes such as forest fires, as well as anthropogenic processes such as incomplete combustion of fossil fuels and biomass (Dat and Chang, 2017), which can enter the natural environment such as water body through a variety of ways (Palm et al., 2004).

With the world's socio-economic development and increasing demand for energy, the high emissions of PAHs pose an increasing threat to global health (Idowu et al., 2019, Kim et al., 2013).

The PAHs in the water environment tend to adsorb in the sediment due to the high PAHs stability, low solubility and strong hydrophobicity (Doong and Lin, 2004). At the same time, due to the frequent substances exchange between the sediment phase and the aqueous phase (including the water and porewater phase), the adsorbed PAHs in sediment phase will also be released into water for biological utilization, resulting in 
secondary pollution and harm to ecological environment and human health (Hussain et al., 2016, Yim et al., 2007, Han et al., 2020). The importance of drinking water reservoirs to human beings is self-evident. However, the reports of PAHs in the water environment are mainly focused on rivers (Doong and Lin, 2004, Sun et al., 2009), lakes (Li et al., 2017, Qiao et al., 2006) and oceans (Araghi et al., 2014, Yuan et al., 2015). There are few comprehensive studies on PAHs in reservoir systems, especially large drinking water reservoirs (Jiao et al., 2009, Seopela et al., 2020) and the soil phase of the water level drop zone of the reservoir. The Fengshuba Reservoir (FSBR) is located at the source of the Dongiiang River Basin in southern China, providing drinking water sources for nearly 40 million people in surrounding cities (Longchuan, Guangzhou and Shenzhen). With the rapid economic development of Dongjiang River Basin (He et al., 2013), the FSBR may be polluted by PAHs, which will threaten the ecological environment and human health in the basin (Zheng et al., 2013). Hence, assessing the occurrence and risk levels of PAHs in the FSBR will become crucial.

The purpose of this study is to systematically explore the occurrence, source, and distribution of 16 USEPA PAHs in water phase, porewater phase, sediment phase and soil phase in FSBR, and at the same time to evaluate the risks of the PAHs in water phase and solid phase of the reservoir to ecology and human health. The relationship between the PAHs and environmental parameters in different environmental media, and finally determined the potential applicability of this potential indicator in the management and control of the PAHs pollution in drinking water reservoirs. These studies contribute to a better understanding of the PAHs environmental behavior in 
reservoir systems and are expected to enrich the study of the PAHs in the water environment.

\section{Materials and Methods}

\subsection{Study area and sampling}

The main water collecting sources of FSBR are Beiling River (basin area: $2363 \mathrm{~km}^{2}$ ) and Xinwu River (basin area: $2697 \mathrm{~km}^{2}$ ). The water surface area of FSBR is about 16.45 $\mathrm{km}^{2}$, and the water depth is between $70 \mathrm{~m}$ and $100 \mathrm{~m}$ (Chen et al., 2017). Table $\mathrm{S} 1$ showed the hydrological information of the reservoir in detail. Samples were taken from five sampling sites (S1-S5) from July 18 to 20, 2015 (summer), November 25 to 27, 2015 (autumn) and March 14 to 16, 2016 (spring), respectively. For the water phase, 3 $\mathrm{L}$ of water samples were taken from the surface $(50 \mathrm{~cm}$ below the water surface), the middle (half of the water depth) and the bottom (2-4 m from the bottom), respectively. And then the three water samples were mixed to form $9 \mathrm{~L}$ of water samples (S1-S5) at the point. For sediment phase, a gravity sedimentation sampler was used to take sediment samples (S1-S5) about $15 \mathrm{~cm}$ from the bottom of the water. In addition, only in March 2016 (spring), when the water yield of the reservoir increased, that is, the water level of the reservoir decreased, the surface soil samples (15 $\mathrm{cm}$ below the surface) were taken from the water level drop zone at the same sampling point (S1-S5) (Chen et al., 2020). In order to minimize sampling errors, samples were collected three times at each sampling site. In addition, the samples were immediately transferred to the laboratory after collection and stored in acidic plastic drums at $-20^{\circ} \mathrm{C}$.

\subsection{Chemicals and standard products}


This study involves the detection and quantification of 16 representative PAHs listed by USEPA. PAHs Standards were classified according to the number of rings: 2-ring PAHs (naphthalene (Nap)), 3-ring PAHs (acenaphthylene (Acy), acenaphthene (Ace), fluorene (Flo), phenanthrene (Phe), anthracene (Ant)), 4-ring PAHs (fluoranthene (Fla), pyrene (Pyr), benzo[a]anthracene (BaA), chrysene (Chr)), 5-ring PAHs (benzo[b]fluoranthene $(\mathrm{BbF})$, benzo[k]fluoranthene $(\mathrm{BkF})$, benzo[a]pyrene $(\mathrm{BaP})$, dibenz[a,h]anthracene (DahA)), 6-ring PAHs (indeno[1,2,3-cd]pyrene (IcdP), benzo[g,h,i]perylene (BghiP)). Standard Solution of the PAHs Isotope Tracer: naphthalene-d8 (Nap-d8), acenaphthylene-d10 (Ace-d10), phenylene-d10 (Phe-d10) and pyrene-d12 (Pyr-d12) were soluble in Methanol. All the abovementioned compounds were purchased from Dr.Ehrenstorfer (Augsburg, Germany). Quantitative internal standard: Anthracene-d10 was purchased from German DR Company as the quantitative internal standard on machine. All the organic reagents in this experiment were chromatography-grade, and the solid phase extraction HC-C18 column was purchased from Shanghai Anpu Experimental Scientific Instrument Co., Ltd. The physical and chemical properties of these 16 USEPA PAHs were listed in Table S2.

\subsection{Environmental Factor Detection}

The sediment samples were centrifuged at $5000 \mathrm{rpm}$ for $10 \mathrm{~min}$ and the supernatant was collected. Porewater is known as the filtrate obtained by filtered the supernatant through a $0.45 \mu \mathrm{m}$ glass fiber filter. Using Hydrolab multi-parameter water quality analyzer (Hash, USA), the temperature (T), oxidation reduction potential (ORP), dissolved oxygen (DO), $\mathrm{pH}$, electrical conductivity (EC), chlorophyll- $\alpha$ (Chl- $\alpha$ ) and 
turbidity of the water samples and porewater samples were measured. Other environmental parameters were measured according to the national standard methods: dissolved total nitrogen (DTN), dissolved organic carbon (DOC), total phosphorus. In addition, the sediment and soil samples were freeze-dried, and then ground and passed through 100-mesh sieve. According to other studies, the basic environmental parameters of the solid phase are T, EC, ORP, $\mathrm{pH}$, total organic carbon (TOC), total nitrogen (TN), total phosphorus (TP), and the percentage of clay, sand and silt.

\subsection{Sample handling and analysis}

\subsubsection{Solid phase extraction of water samples}

The water samples ( $1 \mathrm{~L}$ in triplicate) were filtered by $0.45 \mu \mathrm{m}$ aqueous phase filter membrane, and the filtrate was transferred into brown bottles, and $5 \mathrm{~mL}$ of methanol was added to each bottle, and then a certain amount of standard solution of isotope tracer was added and fully mixed before use. $5 \mathrm{~mL}$ of N-hexane: Dichloromethane (1:1), $5 \mathrm{~mL}$ of methanol, and $5 \mathrm{~mL}$ of distilled water were respectively used to activate the HC-C18 column for 3 min. After connected the large-capacity sampling tube, maintained the flow rate of $3-5 \mathrm{~mL} / \mathrm{min}$ for water sample enrichment. After sample enrichment was completed, the inner wall rinsed by ultrapure water and continued the enrichment. and then use the vacuum pump to drain it after the completion $30 \mathrm{~min}$. Then, use $5 \mathrm{~mL}$ of n-hexane: dichloromethane (1:1), and $5 \mathrm{~mL}$ of dichloromethane were used for elution successively, and the elution was performed for about 3 minutes each time. The eluent was collected in the test tube. Then, when the eluent was concentrated to about $1 \mathrm{~mL}$ with a nitrogen blower, transferred to a quantitative concentration tube, and 
added $3 \mathrm{~mL}$ of n-hexane: acetone (1:1) as the conversion solvent, continued to use the nitrogen blower to concentrate to about $0.3 \mathrm{~mL}$, added $50 \mu \mathrm{L}$ internal standard anthracene-d10 $(800 \mu \mathrm{g} / \mathrm{L})$ made the final concentrated solution $80 \mu \mathrm{g} / \mathrm{L}$, and finally calibrated to $0.5 \mathrm{~mL}$ with $\mathrm{n}$-hexane: acetone $(1: 1)$, and then transferred to a brown machine vial for later use.

\subsubsection{Solid phase extraction of water samples}

For the solid samples (sediment and soil samples), first freeze-dried for 24 hours, ground them in a mortar and pass through a 100-mesh sieve, and then collected them for later use. Then, took $1 \mathrm{~g}$ of the treated samples and $5 \mathrm{~g}$ of diatomite and mixed them thoroughly, and put them into a $0.45 \mu \mathrm{m}$ glass fiber membrane accelerated solvent extraction cell, a certain amount of internal tracer markers was added and left overnight before an accelerated solvent extractor was added. Then put it into an accelerated solvent extraction instrument for extraction. Extraction conditions: the extraction solvent was dichloromethane: acetone: n-hexane $(1: 1: 1, \mathrm{~V} / \mathrm{V} / \mathrm{V})$ mixed solution, pressure $1500 \mathrm{psi}$, temperature $100^{\circ} \mathrm{C}, 5 \mathrm{~min}$ of preheating equilibrium time, $6 \mathrm{~min}$ of static extraction time, the elution volume was $60 \%$ of the volume of the extraction tank, the nitrogen purge time was $60 \mathrm{~s}$, and 2 cycles of extraction process. Finally, the extracted solution was subjected to the same concentration process as the above water sample.

\subsubsection{GC-MS instrumental analysis conditions}

Gas chromatographic conditions: the temperature of the injection port was $280{ }^{\circ} \mathrm{C}$, and splitless sampling; the carrier gas was high-purity helium with a flow rate of 1.0 
$\mathrm{mL} / \mathrm{min}$; heating program: kept at $60{ }^{\circ} \mathrm{C}$ for $2 \mathrm{~min}$, then increased to $210{ }^{\circ} \mathrm{C}$ at the rate of $15{ }^{\circ} \mathrm{C} / \mathrm{min}$ and kept for $2 \mathrm{~min}$, and increased to $300{ }^{\circ} \mathrm{C}$ at the rate of $3{ }^{\circ} \mathrm{C} / \mathrm{min}$ and kept for $2 \mathrm{~min}$, and ran at $315^{\circ} \mathrm{C}$ for $5 \mathrm{~min}$. Mass spectrometry conditions: the temperature of the quadrupole was $150{ }^{\circ} \mathrm{C}$, the temperature of the ion source was $230{ }^{\circ} \mathrm{C}$, and the temperature of the transmission line was $300^{\circ} \mathrm{C}$, and the ionization energy was $70 \mathrm{eV}$. Data collection method: adopt ion scanning mode, in which the solvent delay time was 5 minutes, the peak time of the target compound, the quantification ion and the qualifier ion were listed in Table S3.

Establishment of standard curve: with reference to the above conditions of instrument analysis within the standard method of quantitative, and established standard curves of internal standard method. The quantitative analysis of water samples: the sample was carried out according to the above-mentioned instrument analysis conditions, and quantitative analysis using internal standard method with the curve, and used the tracer recovery rate as the correction factor, and divided by the concentration factor of 2000 , which was the actual concentration (ng/L) of water samples. The quantitative analysis of solid samples: samples with reference to the above analysis instrument analysis conditions. The internal standard method was used to mark the curve for quantitative analysis, and the tracer recovery was used as the correction factor. The concentration in the sample divided by the concentration ratio was the actual concentration in the sediment $(\mu \mathrm{g} / \mathrm{kg})$.

\subsection{Sources of PAH}

A large number of studies have shown that the ratio isomers of the PAHs is of great 
significance for study the source of the PAHs (Hartmann et al., 2004, Zhang et al., 2006, Yunker et al., 2002, Sarria-Villa et al., 2016). These ratios such as Fla/(Fla + Pyr), Phe/Ant, Nap/Phe, Ant/(Ant + Phe), Fla/(Fla + Pyr), InP/(InP + BghiP) can be used to study the sources of the PAHs in water, sediment and soil (Budzinski et al., 1997, Tobiszewski and Namiesnik, 2012). Since no high-ring PAHs such as IcdP and BghiP were detected in the water phase, the ratio of $\mathrm{Fla} /(\mathrm{Fla}+\mathrm{Pyr})$ and $\mathrm{Ant} /(\mathrm{Ant}+\mathrm{Phe})$ were used to study the main sources of water and solid phase of FSBR. The ratio of Fla/(Fla + Pyr) $<0.4$ (De La Torre-Roche et al., 2009) indicates that petroleum sources are dominant, and the ratio of $\mathrm{Flu} /(\mathrm{Flu}+\mathrm{Pyr})$ between 0.4 to 0.5 indicates that liquid petrochemical combustion is dominant, and the ratio of $\mathrm{Fla} /(\mathrm{Fla}+\mathrm{Pyr})>0.5$ indicates that biomass burning such as grass, wood, and coal is dominant. The ratio of Ant/(Ant + Phe) $<0.1$ (Pies et al., 2008) indicates that the petroleum source is dominant, and the ratio of Ant $/(\mathrm{Ant}+\mathrm{Phe})>0.1$ indicates that the pyrolysis source is dominant.

\subsection{Risk assessment}

Ecological risk assessment: the risk quotient (RQ) method was used to evaluate the ecological toxicity of the PAHs in the FSBR (Cao et al., 2010, Zhang et al., 2017, Yu et al., 2021). The risk level of the PAHs was characterized by the RQ, which was defined as follows:

$R Q=\frac{\mathrm{C}_{\mathrm{PAHs}}}{C_{Q v}}$

$\mathrm{C}_{\mathrm{PAHs}}$ and $\mathrm{C}_{\mathrm{Qv}}$ in the above formula were expressed as the actual concentration of certain PAHs in each medium and the corresponding quality value of certain PAHs in each medium. The ratio of the actual concentrations (ACs) of the PAHs to the negligible 
concentrations (NCs) and maximum permissible concentrations (MPCs) of the PAHs in the corresponding medium was used to evaluate the risk level of the PAHs in water, sediment and soil phase, which was defined as follows:

$$
R Q_{N C S}=\frac{\mathrm{C}_{\mathrm{ACS}}}{\mathrm{C}_{\mathrm{NCS}}}
$$

$$
R Q_{M P C S}=\frac{\mathrm{C}_{\mathrm{ACS}}}{\mathrm{C}_{\mathrm{MPCS}}}
$$

Furthermore, according to the current research, the following formulas (4), (5) and (6) were used to calculate $\mathrm{RQ}_{\Sigma \mathrm{PAHs}}, \mathrm{RQ}_{\Sigma \mathrm{PAHs}}$ (NCs) and $\mathrm{RQ} \sum \mathrm{PAHs}$ (MPCs) in various environmental medium, which were defined as follows:

$$
R Q_{\sum P A H S}=\sum_{i=1}^{16} \mathrm{RQ}(\mathrm{RQ}>1)
$$

$R Q_{\sum P A H S(N C S)}=\sum_{i=1}^{16} \mathrm{RQ}_{\mathrm{NCs}}\left(\mathrm{RQ}_{\mathrm{NCs}}>1\right)$

$$
R Q_{\sum P A H S(M P C S)}=\sum_{i=1}^{16} \mathrm{RQ}_{\mathrm{PMCS}}\left(\mathrm{RQ}_{\mathrm{MPCS}}>1\right)
$$

Health risk assessment: the incremental lifetime cancer risk (ILCRs) recommended by USEPA combined with toxic equivalent of $\mathrm{BaP}(\mathrm{TEQ} \mathrm{BaP})$ was used to quantitatively characterize the potential carcinogenic risk of human body by the PAHs in the water of FSBR (Nadal et al., 2004, Meng et al., 2019, Yu et al., 2021). Human body are mainly exposed to the PAHs in surface water and groundwater bodies through ingestion and skin contact, resulting in potential carcinogenic risks. The calculation formulas (3), (4) and (5) are as follows:

$$
\mathrm{TEQ}_{\mathrm{BaP}}=\sum_{i=1}^{16} \mathrm{C}_{\mathrm{i}} \times \mathrm{TEF}
$$

$$
\text { ILCRs }_{\text {ingestion }}=\frac{\mathrm{TEQ}_{\mathrm{BaP}} \times \mathrm{IRW} \times \mathrm{CSF}_{\mathrm{i}} \times \mathrm{EF} \times \mathrm{ED}}{B W \times A T}
$$

$$
\mathrm{ILCRs}_{\text {skin contact }}=\frac{\mathrm{TEQ}_{\mathrm{BaP}} \times \mathrm{SA} \times \mathrm{K}_{\mathrm{p}} \times \mathrm{ABS} \times \mathrm{ET} \times \mathrm{CSF}_{\mathrm{i}} \times \mathrm{EF} \times \mathrm{ED}}{B W \times A T}
$$


represents the incremental lifetime cancer risk caused by ingestion and ILCRs skin contact represents the incremental lifetime cancer risk caused by contact.

\subsection{Data analysis}

Before the statistical analysis of the data, first of all, SPSS 26.0 (IBM, USA) ShapiroWilk test was used to check whether the measured data met the normal distribution, and then the One-way ANOVA test (for normal distribution) or the Kruskal-Wallis test (for non-normal distribution) were used to analyze the inherent correlation of the data. Use Origin 9 software (Originlab, USA) and R language (Microsoft, USA) for data visualization. Use Canoco 5 (Microcomputer Power, UBA) software and R language (Microsoft, USA) to perform redundancy analysis (RDA) and ANOSIM analysis on the measured data of PAHs. If $\mathrm{P}$ value is involved, then $\mathrm{P} \leq 0.05$ or $\mathrm{P} \leq 0.01$ indicates that the test results of the measured data were statistically significant.

\section{Result and discussions}

\subsection{Distribution of the PAHs}

\subsubsection{The PAHs in aqueous phase}

The concentrations of 16 PAHs in the water samples from FSBR were shown in the Fig. 2 (A) and Table S4. Among the 16 PAHs, 6 of the PAHs were not detected (5-ring: $\mathrm{BbF}, \mathrm{BkF}$, BaP, IcdP; 6-ring: DahA, BghiP), the detection rate of $\mathrm{BaA}$ was 50\%, and the detection rate of the remaining PAHs were $100 \%$. The total concentrations of 10 remaining PAHs ( $\sum 10 \mathrm{PAHs}$ ) ranged from $110.04 \mathrm{ng} / \mathrm{L}$ to $389.88 \mathrm{ng} / \mathrm{L}$, with an average of $213.14 \mathrm{ng} / \mathrm{L}$ and a median of $198.37 \mathrm{ng} / \mathrm{L}$. Therefore, it can be seen from the results that the FSBR as a source of drinking water had been contaminated. Among these 10 
PAHs, the concentration of Nap ranged from 62.09 to $256.44 \mathrm{ng} / \mathrm{L}$ (average: 125.72 ng/L, median: $138.44 \mathrm{ng} / \mathrm{L}$ ), which was significantly higher than others, indicating that Nap abound in the reservoir. The possible reason was that Nap has the highest solubility in water (Tobiszewski and Namiesnik, 2012). In addition, the 5-ring and 6-ring PAHs were not detected in any water samples because of their extremely low solubility in water, which makes it easier for high-ring PAHs to be enriched in the solid phase. This phenomenon also occurs in the Moscow River, Russia water body, which the high-ring PAHs were not detected (Eremina et al., 2016). Comparing with other studies, the total concentration of the PAHs in the water phase of FSBR was similar to the total concentration of the PAHs in Luan River Basin, China ( $\sum$ PAHs: 9.75-309.75 ng/L) (Li et al., 2010), which was higher than that in River Tiber, Italy $(23.9-72.0 \mathrm{ng} / \mathrm{L}$ ) (Patrolecco et al., 2010), Ili-Balkhash Basin, arid Central Asia (7.58-70.98 ng/L) (Shen et al., 2021), and lower than that in Loskop dam, South Africa $(0.150-49.8 \mu \mathrm{g} / \mathrm{L})$ (Seopela et al., 2020).

In porewater samples (Fig. 2 (B) and Table S4), except for the detection rate of IcdP and DahA at $93.3 \%$, the detection rate of the remaining 14 PAHs was $100 \%$. The total concentrations of the 16 USEPA the PAHs ( $\left.\sum 16 \mathrm{PAHs}\right)$ ranged from $5.75 \mu \mathrm{g} / \mathrm{L}$ to 34.96 $\mu \mathrm{g} / \mathrm{L}$, with an average of $18.33 \mu \mathrm{g} / \mathrm{L}$ and a median of $18.56 \mu \mathrm{g} / \mathrm{L}$. These data were significantly higher than those in the water phase, mainly because of sediments. The sediment phase was also a sink of the PAHs in the water body, and the porewater was obtained by centrifugation of the sediment phase (Bigus et al., 2014, Guo et al., 2017). In fact, this was consistent with what has been reported by other studies (Maskaoui et 
290

291

292

293

294

295

296

297

298

299

300

301

302

303

304

305

306

307

308

309

310

311

al., 2002). Similar to the aqueous phase, the concentration of Nap was also the highest (average: $9.42 \mu \mathrm{g} / \mathrm{L}$, median: $10.16 \mu \mathrm{g} / \mathrm{L})$, followed by Phe $(2.80 \mu \mathrm{g} / \mathrm{L}, 2.88 \mu \mathrm{g} / \mathrm{L})$ in porewater phase of FSBR. Looking at the water and porewater phase, it can be inferred that the PAHs in the water phase were an important source of PAHs in the porewater phase. Comparing with other studies, the total concentration of the PAHs in the sediments of FSBR was higher than that in Lake Taihu, China ( $\sum 16$ PAHs: 2.01-19.90 $\mu \mathrm{g} / \mathrm{L}$ ) (Zhang et al., 2011), and lower than that in Lanzhou Reach of Yellow River, China (48.2-206 $\mu \mathrm{g} / \mathrm{L})$ (Yu et al., 2009).

\subsubsection{PAHs in solid phase}

As shown in Fig. 2 (C) and Table S4, all 16 PAHs were detected in all sediment samples. The total concentrations of these 16 PAHs ( $\sum 16$ PAHs) ranged from 364.4 $\mu \mathrm{g} / \mathrm{kg}$ to $743.71 \mu \mathrm{g} / \mathrm{kg}$, with an average of $506.81 \mu \mathrm{g} / \mathrm{kg}$ and a median of $470.22 \mu \mathrm{g} / \mathrm{kg}$. Similar to the occurrence of the PAHs in the porewater phase, the concentration of Nap $(114.43 \mu \mathrm{g} / \mathrm{kg}, 120.77 \mu \mathrm{g} / \mathrm{kg})$ and Phe $(112.26 \mu \mathrm{g} / \mathrm{kg}, 74.57 \mu \mathrm{g} / \mathrm{kg})$ were significantly higher than the others. Due to the occurrence of the PAHs in aqueous phase, Nap and Phe may have a tendency to accumulate from aqueous phase to sediment phase (Han et al., 2020). Comparing with other studies, the total concentration of the PAHs in the sediments of FSBR higher than that in Chenab River, Pakistan ( $\sum 16$ PAHs: 7.41-600 $\mu \mathrm{g} / \mathrm{kg}$ ) (Hussain et al., 2016), Gorgan Bay, Caspian Sea (107.87-516.18 $\mu \mathrm{g} / \mathrm{kg}$ ) (Araghi et al., 2014), and lower than that in Dianchi Lake, China (210-11070 $\mu \mathrm{g} / \mathrm{kg})(\mathrm{Zhao}$ et al., 2014) and Loskop dam, South Africa (61.6-2618 $\mu \mathrm{g} / \mathrm{kg}$ ) (Seopela et al., 2020). For the solid phase (Fig. 2 (D) and Table S4), the 16 PAHs were detected in all 
samples. The total concentration of these $16 \mathrm{PAHs}\left(\sum 16 \mathrm{PAHs}\right)$ ranged from 367.81 $\mu \mathrm{g} / \mathrm{kg}$ to $639.89 \mu \mathrm{g} / \mathrm{kg}$, with an average of $485.18 \mu \mathrm{g} / \mathrm{kg}$ and a median of $453.29 \mu \mathrm{g} / \mathrm{kg}$. Comparing with the sediment, the overall occurrence level of PAHs in the soil phase in the drawdown area was similar to that in the sediment phase. The distribution of the PAHs in soil phase of FSBR was closely related to human activities (Li et al., 2020). There are more intensive human activities at S5, including agriculture, fishing and fish breeding, while the human activities at S4 were lesser. Among them, the point with the highest concentration was $\mathrm{S} 5(528.18 \mu \mathrm{g} / \mathrm{kg})$, and the point with the lowest concentration was S4 $(400.33 \mu \mathrm{g} / \mathrm{kg})$. Similar to the occurrence of the PAHs in porewater and sediment samples, the Nap $(170.25 \mu \mathrm{g} / \mathrm{kg}, 154.92 \mu \mathrm{g} / \mathrm{kg})$ and Phe $(108.43 \mu \mathrm{g} / \mathrm{kg}, 100.98 \mu \mathrm{g} / \mathrm{kg}$ ) have the highest concentration. It can be seen from the results that the occurrence of Nap and Phe in soil phase was the same as that of Nap and Phe in water and sediment phase, which also proves that PAHs are more likely to be deposited in solid phase in water environment (Doong and Lin, 2004). However, since there are few reports on the occurrence of PAHs in the soil in the drawdown area of reservoirs, the results of this study cannot be compared with those of other studies. At the same time, it also reflects that the pollution of PAHs in soil in water-leveling and fluctuating areas is worthy of further study, especially for those large drinking water reservoirs.

\subsection{Sources of PAHs}

For the water phase, from Fig. 3 (A) and Table S5, the ratio of Fla/(Fla + Pyr) in the water samples was $0.54-0.63>0.5$, indicating that the PAHs in the water phase were 
mainly derived from grass, wood and coal combustion, and the ratio of Ant/(Ant + Phe) in the water samples was $0.03-0.22$, indicating that the PAHs in the water phase also came from combustion of petroleum. For the porewater phase, according to Fig. 3 (B) and Table S5, the ratio of Fla/(Fla + Pyr) in the porewater samples was $0.58-0.70>0.5$, indicating that the PAHs in the porewater phase were mainly derived from the grass, wood and coal combustion and the ratio of Ant/(Ant + Phe) in the porewater samples was almost all $<0.1$, indicating that PAHs in the porewater phase were also mainly derived from petroleum sources. For the sediment phase (Fig. 3 (C) and Table S5), the ratio of $\mathrm{Fla} /(\mathrm{Fla}+\mathrm{Pyr})$ in sediment samples was $0.52-0.57>0.5$, indicating that the PAHs in the sediment phase were derived from the grass, wood and coal combustion and the ratio of Ant/(Ant + Phe $)$ in the sediment samples was 0.82-0.94 $>0.1$, indicating that the PAHs in the sediment phase were mainly derived from combustion. For the soil phase, according to Fig. 3 (D) and Table S5, the ratio of Flu/(Flu + Pyr) in soil samples was $0.46-0.56$, indicating that the PAHs in the soil phase were mainly derived from the mixed sources of petroleum combustion and grass, wood and coal combustion, and the ratio of Ant/(Ant + Phe $)$ in the soil samples were $0.88-0.96>0.1$, indicating that PAHs in the soil phase were also mainly derived from combustion. In conclusion, the PAHs in FSBR were mainly derived from biomass combustion sources such as grass, wood and coal, which may be due to the fact that FSBR is located in the natural environment area at the source of Dongjiang River, far away from mega-cities such as Guangzhou, Shenzhen and Hong Kong, and the forest coverage rate of Dongjiang River Basin reached $71.8 \%$ in 2009 (Ding et al., 2016). Compared with the four water bodies' bank 
in Jamshedpur, India, where urbanization was accelerating, the main source of PAHs in water bodies was related to combustion and diagenesis (Ambade and Sethi, 2021), and for the Lake Ijssel, the Netherlands (Niu and van Gelder, 2020), its water source mainly comes from the Rhine River and passes through big cities like Amsterdam, making the PAHs in the lake mainly come from the coal combustion and petroleum source.

\subsection{Seasonal variations of PAHs in reservoirs}

For the water phase, the concentration of 2-ring PAHs in spring $(191.45 \pm 75.00 \mathrm{ng} / \mathrm{L})$ was significantly lower than the concentration of 2-ring PAHs in summer $(125.20 \pm$ $11.46 \mathrm{ng} / \mathrm{L})$ and autumn $(96.64 \pm 23.83 \mathrm{ng} / \mathrm{L})($ one-way ANOVA, $\mathrm{F}=5.42, \mathrm{P}<0.05)$ (Fig. 4 (A)). The concentration of 3-ring PAHs in autumn $(38.79 \pm 5.51 \mathrm{ng} / \mathrm{L})$ was also significantly lower than the concentration of 3-ring PAHs in summer $(58.88 \pm 3.35 \mathrm{ng} / \mathrm{L})$ and spring $(63.39 \pm 13.17 \mathrm{ng} / \mathrm{L})$ (one-way ANOVA, $\mathrm{F}=11.96, \mathrm{P}<0.01)$. The concentration of 4-ring PAHs in summer $(17.38 \pm 1.47 \mathrm{ng} / \mathrm{L})$ was lower than the concentration of 4-ring PAHs in spring (23.25 $\pm 5.31 \mathrm{ng} / \mathrm{L})$ (one-way ANOVA, F = 5.61, $\mathrm{P}<0.05)$. In addition, this distribution trend was similar to the order of local rainfall: Autumn $(28.5 \mathrm{~mm})<$ Summer $(218 \mathrm{~mm})<$ Spring $(316 \mathrm{~mm})$ (Table S1). It also indicated that season had a significant effect on the distribution of total concentration of PAHs in the aqueous phase (Li et al., 2020).

For the PAHs in the porewater phase, the concentrations of 3-ring PAHs hydrocarbons in spring $(4.71 \pm 0.81 \mu \mathrm{g} / \mathrm{L})$ were lower than those in summer $(5.75 \pm$ $0.22 \mu \mathrm{g} / \mathrm{L})$ and autumn $(5.60 \pm 0.68 \mu \mathrm{g} / \mathrm{L})$ (one-way ANOVA, $\mathrm{F}=4.14, \mathrm{P}<0.043)($ Fig. 3 (B)). The concentration of 6- ring PAHs in spring $(0.04 \pm 0.01 \mu \mathrm{g} / \mathrm{L})$ was significantly 
lower than that of 6-ring PAHs in summer $(0.19 \pm 0.12 \mu \mathrm{g} / \mathrm{L})$ and autumn $(0.06 \pm 0.03)$ (one-way ANOVA, $\mathrm{F}=6.57, \mathrm{P}<0.05$ ). In addition, the variation trend of the total concentration of the PAHs was similar to that of Hydraulic retention time (days) in FSBR: 49 days in spring $<122$ days in summer $<246$ days in autumn (Table S1).

For the PAHs in sediments, the concentration of 2-ring PAHs in autumn $(88.26 \pm$ $29.30 \mu \mathrm{g} / \mathrm{kg}$ ) was significantly lower than that in spring (114.43 $\pm 24.45 \mu \mathrm{g} / \mathrm{kg})$ (oneway ANOVA, $\mathrm{F}=6.10, \mathrm{P}<0.05)(\mathrm{Fig3}(\mathrm{C})$ ). The 3-ring PAHs concentrations in summer $(253.98 \pm 53.14 \mu \mathrm{g} / \mathrm{kg})$ were significantly higher than those in autumn $(124.16$ $\pm 11.08 \mu \mathrm{g} / \mathrm{kg}$ ) and spring $(120.15 \pm 7.21 \mu \mathrm{g} / \mathrm{kg})$ (Kruskal-Wallis $\mathrm{H}, \mathrm{P}<0.05)$. The concentrations of 6-ring PAHs in summer $(27.40 \pm 2.78 \mu \mathrm{g} / \mathrm{kg})$ were significantly higher than those in spring $(22.88 \pm 1.83 \mu \mathrm{g} / \mathrm{kg})$ (one-way ANOVA, $\mathrm{F}=4.17, \mathrm{P}<0.05$.).

It is worth noting that there were significant differences in the PAH composition between the water phase and the pore water phase and the sediment and soil phases (ANOSIM, $\mathrm{P}<0.01$ ). It was further confirmed that the environmental behavior of the PAHs in storage systems with different environmental media was complex and diverse. At the same time, this also emphasized that when facing the problem of the PAHs pollution in large drinking water reservoirs, we should comprehensively consider the impact of multiple environmental media (environmental factors) on their environmental behavior.

\subsection{Relationship between environmental parameters and PAHs}

Redundancy analysis (RDA) is a commonly used multivariate analysis method that can be used to analyze the relationship between two sets of variables (Takane and 
400

401

402

403

404

405

406

407

408

409

410

411

412

413

414

415

416

417

418

419

420

421

Hwang, 2005). This study used RDA to further explore the relationship between environmental parameters and the PAHs in various media of FSBR (Opere et al., 2020).

The blue arrows indicate specific PAHs, and the red arrows indicate specific environmental parameters. And these environmental parameters are shown in detail in Table S5-S8.

For the water phase, the RDA results (Fig. 5 (A)) showed that $49.7 \%$ of the changes in PAHs were explained by these five significant environmental parameters: NTU $(24.0 \%, \mathrm{P}=0.002), \mathrm{NO}_{2}^{-}(20.3 \%, \mathrm{P}=0.004), \mathrm{Chl}-\alpha(16.4 \%, \mathrm{P}=0.002), \mathrm{NH}_{4}{ }^{+}(5.3 \%$, $\mathrm{P}=0.036), \mathrm{IC}(4.3 \%, \mathrm{P}=0.05)$. This result indicated that these environmental parameters have a significant impact on the distribution of the PAHs in the water phase of the FSBR. At the same time, it was worth noting that NTU and Chl- $\alpha$ were related to turbidity, thus affecting the photodegradation of PAHs in water (Sanches et al., 2011). The distribution of PAHs in the porewater phase was slightly affected by environmental parameters, such as $\mathrm{pH}(4.0 \%, \mathrm{P}=0.09)$ and $\mathrm{NO}_{3}{ }^{-}(3.0 \%, \mathrm{P}=0.166)$, and the $\mathrm{P}$ value was greater than 0.05 for porewater phase (Fig. 5 (B)). For the sediment phase, the RDA results showed (Fig. 5 (C)) that $26.8 \%$ of the changes in PAHs can be explained by environmental parameters, such as $\mathrm{T}(35.6 \%, \mathrm{P}=0.002)$ and $\mathrm{NO}_{3}{ }^{-}(17.9 \%, \mathrm{P}=0.006)$. For the soil in the drawdown zone, the results of RDA showed (Fig. 4 (D)) that these environmental parameters have little effect on the PAHs in the soil in the drawdown zone of FSBR, but the changes in $\mathrm{pH}, \mathrm{DOC}$, TOC and NO3- had significant influence on the distribution of Acy.

\subsection{Pseudo-partitioning coefficient calculation}



and aqueous phase (water and porewater phase), the pseudo-partition coefficient $(P-P C)$ method (Bai et al., 2014) was used. According to the following formula to explore their distribution behaviors: $P-P C s, w$ (sediment phase to water phase) $=C s / C w, P-P C s, p$ (sedimentary phase to porewater phase) $=C s / C p$, where $C s, C w$ and $C p$ refer to the actual measured concentration of the PAHs in sediment phase $(\mu \mathrm{g} / \mathrm{kg})$, water phase $(\mu \mathrm{g} / \mathrm{L})$ and porewater phase $(\mu \mathrm{g} / \mathrm{L})$, respectively. The data of $P-P C s, w$ and $P-P C s, p$ were shown in Table S9 and S10.

At the same time, some studies have reported that the distribution of the PAHs between sediment and aqueous phase may also be affected by basic environmental factors (such as pH, TOC and DOC) (Ekpo et al., 2012, Nascimento et al., 2017). In this study, Pearson analysis was used to explore the relationship between $P-P C(\log P-$ $P C s, w$ and $\log P-P C s, p)$ and the level of $\mathrm{pH}$ in the corresponding system. In the sediment to water phase system, only the value of Phe $(\log P-P C s, w)$ and the $\mathrm{pH}$ value of water phase were positively correlated. It was indicated that the $\mathrm{pH}$ of water phase may affect the distribution behavior of Phe between water phase and sediment phase, while other target PAHs had no significant correlation with the level of $\mathrm{pH}$. In the sediment to porewater system, it can be seen that the values of Ant, Fla, Pyr, BkF, BaP and DahA $(\log P-P C s, p)$ were positively correlated with the $\mathrm{pH}$ of the porewater phase, while the values of Flo and Phe $(\log P-P C s, p)$ were negatively correlated with the $\mathrm{pH}$ of porewater (Fig. 6), indicating that the $\mathrm{pH}$ of porewater may affect the distribution of 
sedimentary phase.

\subsection{Ecological and health risk assessment}

\subsubsection{Ecological Risk Assessment}

Table S11 and Fig. 7 showed the NCs and MECs of the 16 USEPA PAHs in different environmental media, as well as the RQ $\mathrm{NCs}_{\text {, }}$ RQMECs and $\mathrm{RQ}_{\Sigma \mathrm{PAHs}}$ of the USEPA PAHs in water phase, sediment phase and soil phase of FSBR. As can be seen from Table S11, 12 and Fig. 7, RQNCs and RQMECs in the water samples were both significantly greater than 1 , and RQMECs were also significantly lower than 1 . Meanwhile, the total RQ of PAHs in the water phase of FSBR were found to be $\mathrm{RQ}_{\Sigma \mathrm{PAH}(\mathrm{NCs})}=88.88$ and $\mathrm{RQ}_{\Sigma \mathrm{PAH}(\mathrm{MECs})}=0$, therefore, the PAHs in the water phase of FSBR was in a state of Low-risk (Tobiszewski and Namiesnik, 2012). The value of $\mathrm{RQ}_{\mathrm{NCs}}$ of $\mathrm{Chr}, \mathrm{BkF}, \mathrm{BaP}$, IcdP, BghiP in sediment samples were approximately 0 and the value of RQMECs were almost 0 , so their impact on the ecological environment was very low, while the other PAHs were in a state of Moderate-risk. And the total RQ of the PAHs in the sediment phase were found to be $\mathrm{RQ}_{\Sigma \mathrm{PAH}(\mathrm{NCs})}=276.30$ and $\mathrm{RQ}_{\Sigma \mathrm{PAH}(\mathrm{MECs})}=0$, so the PAHs of the sediment phase in FSBR was in a state of Low-risk level. The value of RQ $\mathrm{NCs}_{\mathrm{s}}$ of $\mathrm{Chr}$, BkF, IcdP, and BghiP in the soil samples were approximately 0 and the value of RQMECs were almost 0 , which had a very low impact on the ecological environment, and other PAHs were in a state of Moderate-risk in the ecological environment, except for Nap $\left(\mathrm{RQ}_{\mathrm{NCs}}=121.60, \mathrm{RQ}_{\mathrm{MECs}}=1.22\right)$ was in a High-risk state. And the total RQ of PAHs in the soil phase of the drawdown zone were found to be $\mathrm{RQ}_{\Sigma \mathrm{PAH}(\mathrm{NCs})}=324.22$ and $\mathrm{RQ}_{\Sigma \mathrm{PAH}(\mathrm{MECs})}=1.22$, therefore, the PAHs in the soil phase of FSBR was in a Moderate- 
risk1 state (Table S13). Compared with the FSBR in the nature reserve, the RQs study of PAHs in coastline waters on Khark Island, SW Iran (Akhbarizadeh et al., 2016) that is affected by the petroleum industry shows that PAHs are at a medium to high potential risk. This also reflects from the side that it was very correct to list the FSBR as a protected area (Chen et al., 2019).

\subsubsection{Health risk assessment}

According to equations (7), (8) and (9) and other parameters listed in Table S13, the total carcinogenic risk ( $\sum$ ILCRs) of PAHs in the FSBR was $4.53 \times 10^{-8} \mathrm{a}^{-1}$ to $2.27 \times 10^{-7}$ $\mathrm{a}^{-1}$, with an average of $9.34 \times 10^{-8} \mathrm{a}^{-1}$ and a median of $8.07 \times 10^{-8} \mathrm{a}^{-1}$. The carcinogenic risk value (ILCRsintake) produced by direct ingestion was $4.53 \times 10^{-8} \mathrm{a}^{-1}$ to $2.27 \times 10^{-7} \mathrm{a}^{-1}$, with an average of $9.34 \times 10^{-8} \mathrm{a}^{-1}$ and a median of $8.07 \times 10^{-8} \mathrm{a}^{-1}$; the carcinogenic risk value (ILCRs skin contact) produced through skin contact was $1.30 \times 10^{-13} \mathrm{a}^{-1}$ to $6.53 \times 10^{-13}$ $\mathrm{a}^{-1}$, with an average of $2.68 \times 10^{-13} \mathrm{a}^{-1}$ and a median of $2.32 \times 10^{-13} \mathrm{a}^{-1}$. By comparison, it can be concluded that the risk of carcinogenesis through ingestion was about 100 times that of skin exposure. The total carcinogenic risk ( $\sum$ ILCRs) of PAHs in the water of FSBR was significantly lower than the carcinogenic risk recommended by USEPA ( $10^{-}$

${ }^{6}-10^{-4} \mathrm{a}^{-1}$ ), indicating that the impact of PAHs on health risks was negligible. Compared with the PAHs in the Shitoumen Reservoir, China (Sun et al., 2015) that posed a potential carcinogenic risk to local residents, the PAHs in the water body of the FSBR had almost no harm to the surrounding residents.

\section{Conclusions}

The total concentrations of 16 USEPA PAHs in water phase, porewater phase, 
sediment phase and soil phase of FSBR ranged from $109.72-393.19 \mathrm{ng} / \mathrm{L}, 5.75-35.15$ $\mu \mathrm{g} / \mathrm{L}, 364.4-743.71 \mu \mathrm{g} / \mathrm{kg}, 367.81-639.89 \mu \mathrm{g} / \mathrm{kg}$, respectively. The Nap was the dominant PAHs in the water phase, while it was Nap and Phe were dominant in porewater, sediment and soil phase. The main sources of PAHs in FSBR were grass, wood, biomass and coal combustion. In addition, the distribution of the PAHs in the water phase was affected by seasonal hydrological conditions, and Redundancy analysis showed that, the PAHs in the water phase was also affected by environmental parameters such as turbidity, $\mathrm{NO}_{2}^{-}, \mathrm{NH}_{4}^{+}, \mathrm{Chl}-\alpha$ and IC. The distribution of the PAHs in sediment phase was affected by $\mathrm{T}$ and $\mathrm{NO}_{3}{ }^{+}$, while the PAHs in porewater and soil phase was slightly affected by environmental parameters. Pseudo-partitioning coefficients indicated that the PAHs in the porewater phase were more likely to migrate to the sediment phase. Risk assessment showed that the PAHs in the water and sediment phases were generally in a Low-risk state, while the PAHs in the soil phase were

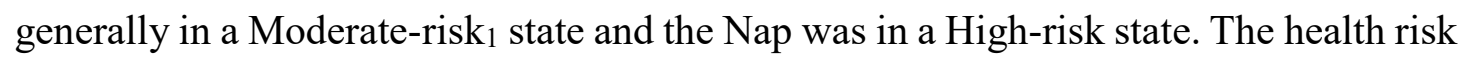
assessment indicated that exposure to the PAHs in FSBR through drinking and skin exposure had little impact on consumers' health. In summary, Nap could be used as a key indicator to evaluate the existence and potential risk of PAHs in FSBR.

Acknowledgements: The authors are grateful for the financial support from the National Natural Science Foundation of China (Grant No. 42007330), and National Science and Technology Major Projects of Water Pollution Control and Management of China (Grant No. 2014ZX07206001).

Conflicts of Interest: The authors declare no conflicts of interest. 


\section{Declaration}

511

512

513

514

515

516

517

518

519

520

521

522

523

524

525

526

527

528

529

530

531

532

533

534

535

536

- Ethics approval and consent to participate Not applicable

- Consent for publication Not applicable

- Availability of data and materials

1. The datasets generated during and/or analysed during the current study are available from the corresponding author on reasonable request.

2. All data generated or analysed during this study are included in this published article (and its supplementary information files).

- Competing interests

The authors declare that they have no competing interests.

- Funding

1. National Natural Science Foundation of China (Grant No. 42007330)

2. National Science and Technology Major Projects of Water Pollution Control and Management of China (Grant No. 2014ZX07206001).

- Authors' contributions

Yiliang He and Kangping Cui conceived of the presented idea. Material preparation, data collection and analysis were performed by Yihan Chen. The first draft of the manuscript was written by Xiangyang Xu. Xing Chen, Zhi Guo, Hongjie Chen and Guangwei Deng commented on previous versions of the manuscript. All authors read and approved the final manuscript. 


\section{Reference:}

Akhbarizadeh, R., Moore, F., Keshavarzi, B. \& Moeinpour, A. (2016) Aliphatic and polycyclic aromatic hydrocarbons risk assessment in coastal water and sediments of Khark Island, SW Iran. Mar Pollut Bull, 108 (1-2), 33-45. https://doi.org/10.1016/j.marpolbul.2016.05.004

Ambade, B. \& Sethi, S. S. (2021) Health Risk Assessment and Characterization of Polycyclic Aromatic Hydrocarbon from the Hydrosphere. Journal of Hazardous, Toxic, and Radioactive Waste, 25 (2). https://doi.org/10.1061/(ASCE)HZ.2153-5515.0000586

Araghi, P. E., Bastami, K. D. \& Rahmanpoor, S. (2014) Distribution and sources of polycyclic aromatic hydrocarbons in the surface sediments of Gorgan Bay, Caspian Sea. Mar Pollut Bull, 89 (1-2), 494-498. https://doi.org/10.1016/j.marpolbul.2013.12.001

Bai, Y., Meng, W., Xu, J., Zhang, Y., Guo, C., Lv, J. \& Wan, J. (2014) Occurrence, distribution, environmental risk assessment and source apportionment of polycyclic aromatic hydrocarbons (PAHs) in water and sediments of the Liaohe River Basin, China. Bull Environ Contam Toxicol, 93 (6), 744-751. https://doi.org/10.1007/s00128-014-1390-7

Bianco, F., Race, M., Papirio, S. \& Esposito, G. (2020) Removal of polycyclic aromatic hydrocarbons during anaerobic biostimulation of marine sediments. Sci Total Environ, 709, 136141. https://doi.org/10.1016/j.scitotenv.2019.136141

Bigus, P., Tobiszewski, M. \& Namiesnik, J. (2014) Historical records of organic pollutants in sediment cores. Mar Pollut Bull, 78 (1-2), 26-42. https://doi.org/10.1016/j.marpolbul.2013.11.008

Budzinski, H., Jones, I., Bellocq, J., Piérard, C. \& Garrigues, P. (1997) Evaluation of sediment contamination by polycyclic aromatic hydrocarbons in the Gironde estuary. Marine Chemistry, 58 (1), 85-97. https://doi.org/10.1016/S0304-4203(97)00028-5

Cao, H., Chao, S., Qiao, L., Jiang, Y., Zeng, X. \& Fan, X. (2017) Urbanization-related changes in soil PAHs and potential health risks of emission sources in a township in Southern Jiangsu, China. Sci Total Environ, 575, 692-700. https://doi.org/10.1016/j.scitotenv.2016.09.106

Cao, Z., Liu, J., Luan, Y., Li, Y., Ma, M., Xu, J. \& Han, S. (2010) Distribution and ecosystem risk assessment of polycyclic aromatic hydrocarbons in the Luan River, China. Ecotoxicology, 19 (5), 827-837. https://doi.org/10.1007/s10646-010-0464-5

Chen, Y., Cui, K., Huang, Q., Guo, Z., Huang, Y., Yu, K. \& He, Y. (2020) Comprehensive insights into the occurrence, distribution, risk assessment and indicator screening of antibiotics in a large drinking reservoir system. Sci Total Environ, 716, 137060.https://doi.org/10.1016/j.scitotenv.2020.137060

Chen, Y., Li, P., Huang, Y., Yu, K., Chen, H., Cui, K., Huang, Q., Zhang, J., Yew-Hoong Gin, K. \& He, Y. (2019) Environmental media exert a bottleneck in driving the dynamics of antibiotic resistance genes in modern aquatic environment. Water Res, 162, 127 138.https://doi.org/10.1016/j.watres.2019.06.047

Chen, Y., Yu, K., Zhou, Y., Ren, L., Kirumba, G., Zhang, B. \& He, Y. (2017) Characterizing spatiotemporal variations of chromophoric dissolved organic matter in headwater catchment of a key drinking water source in China. Environ Sci Pollut Res Int, 24 (36), 2779927812.https://doi.org/10.1007/s11356-017-0307-5

Dat, N. D. \& Chang, M. B. (2017) Review on characteristics of PAHs in atmosphere, anthropogenic sources and control technologies. Sci Total Environ, 609, 682-693. https://doi.org/10.1016/j.scitotenv.2017.07.204 
De La Torre-Roche, R. J., Lee, W. Y. \& Campos-Diaz, S. I. (2009) Soil-borne polycyclic aromatic hydrocarbons in El Paso, Texas: analysis of a potential problem in the United States/Mexico border region. $J$ Hazard Mater, $163 \quad$ (2-3), 946-958. https://doi.org/10.1016/j.jhazmat.2008.07.089

Ding, J., Jiang, Y., Liu, Q., Hou, Z., Liao, J., Fu, L. \& Peng, Q. (2016) Influences of the land use pattern on water quality in low-order streams of the Dongjiang River basin, China: A multi-scale analysis. Sci Total Environ, 551-552, 205-216. https://doi.org/10.1016/j.scitotenv.2016.01.162

Doong, R. A. \& Lin, Y. T. (2004) Characterization and distribution of polycyclic aromatic hydrocarbon contaminations in surface sediment and water from Gao-ping River, Taiwan. Water Res, 38 (7), 1733-1744. https://doi.org/10.1016/j.watres.2003.12.042

Ekpo, B. O., Oyo-Ita, O. E., Oros, D. R. \& Simoneit, B. R. (2012) Distributions and sources of polycyclic aromatic hydrocarbons in surface sediments from the Cross River estuary, S.E. Niger Delta, Nigeria. Environ Monit Assess, 184 (2), 1037-1047. https://doi.org/10.1007/s10661-011-20195

El-Saeid, M. H., Al-Turki, A. M., Nadeem, M. E., Hassanin, A. S. \& Al-Wabel, M. I. (2015) Photolysis degradation of polyaromatic hydrocarbons (PAHs) on surface sandy soil. Environ Sci Pollut Res Int, 22 (13), 9603-9616. https://doi.org/10.1007/s11356-015-4082-x

Eremina, N., Paschke, A., Mazlova, E. A. \& Schuurmann, G. (2016) Distribution of polychlorinated biphenyls, phthalic acid esters, polycyclic aromatic hydrocarbons and organochlorine substances in the Moscow River, Russia. Environ Pollut, 210, 409-418. https://doi.org/10.1016/j.envpol.2015.11.034

Guo, J., Chen, J. \& Wang, J. (2017) Sedimentary records of polycyclic aromatic hydrocarbons in China: A comparison to the worldwide. Critical Reviews in Environmental Science and Technology, 47 (17), 1612-1667. https://doi.org/10.1080/10643389.2017.1393262

Han, B., Liu, A., He, S., Li, Q. \& Zheng, L. (2020) Composition, content, source, and risk assessment of PAHs in intertidal sediment in Shilaoren Bay, Qingdao, China. Mar Pollut Bull, 159, 111499. https://doi.org/10.1016/j.marpolbul.2020.111499

Han, J., Liang, Y., Zhao, B., Wang, Y., Xing, F. \& Qin, L. (2019) Polycyclic aromatic hydrocarbon (PAHs) geographical distribution in China and their source, risk assessment analysis. Environ Pollut, 251, 312-327. https://doi.org/10.1016/j.envpol.2019.05.022

Hartmann, P. C., Quinn, J. G., Cairns, R. W. \& King, J. W. (2004) The distribution and sources of polycyclic aromatic hydrocarbons in Narragansett Bay surface sediments. Mar Pollut Bull, 48 (3-4), 351-358. https://doi.org/10.1016/j.marpolbul.2003.08.014

He, Y., Lin, K. \& Chen, X. (2013) Effect of Land Use and Climate Change on Runoff in the Dongjiang Basin of South China. Mathematical Problems in Engineering, 2013, 1-14. https://doi.org/10.1155/2013/471429

He, Y., Yang, C., He, W. \& Xu, F. (2020) Nationwide health risk assessment of juvenile exposure to polycyclic aromatic hydrocarbons (PAHs) in the water body of Chinese lakes. Sci Total Environ, 723, 138099. https://doi.org/10.1016/j.scitotenv.2020.138099

Hussain, I., Syed, J. H., Kamal, A., Iqbal, M., Eqani, S. A., Bong, C. W., Taqi, M. M., Reichenauer, T. G., Zhang, G. \& Malik, R. N. (2016) The relative abundance and seasonal distribution correspond with the sources of polycyclic aromatic hydrocarbons (PAHs) in the surface sediments of Chenab River, Pakistan. Environ Monit Assess, 188 (6), 378. https://doi.org/10.1007/s10661-016-5359-3 
Idowu, O., Semple, K. T., Ramadass, K., O'Connor, W., Hansbro, P. \& Thavamani, P. (2019) Beyond the obvious: Environmental health implications of polar polycyclic aromatic hydrocarbons. Environ Int, 123, 543-557. https://doi.org/10.1016/j.envint.2018.12.051

Jiao, W., Lu, Y., Wang, T., Li, J., Han, J., Wang, G. \& Hu, W. (2009) Polycyclic aromatic hydrocarbons in soils around Guanting Reservoir, Beijing, China. Chemistry and Ecology, 25 (1), 39-48. https://doi.org/10.1080/02757540802657193

Keith, L. \& Telliard, W. (1979) ES\&T Special Report: Priority pollutants: I-a perspective view. Environmental Science \& Technology, 13 (4), 416-423. https://doi.org/10.1021/es60152a601

Kim, K. H., Jahan, S. A., Kabir, E. \& Brown, R. J. (2013) A review of airborne polycyclic aromatic hydrocarbons (PAHs) and their human health effects. Environ Int, 60, 71-80. https://doi.org/10.1016/j.envint.2013.07.019

Li, C., Huo, S., Yu, Z., Xi, B., Yeager, K. M., He, Z., Ma, C., Zhang, J. \& Wu, F. (2017) National investigation of semi-volatile organic compounds (PAHs, OCPs, and PCBs) in lake sediments of China: Occurrence, spatial variation and risk assessment. Sci Total Environ, 579, 325-336. https://doi.org/10.1016/j.scitotenv.2016.11.097

Li, R., Hua, P., Zhang, J. \& Krebs, P. (2020) Effect of anthropogenic activities on the occurrence of polycyclic aromatic hydrocarbons in aquatic suspended particulate matter: Evidence from Rhine and Elbe Rivers. Water Res, 179, 115901. https://doi.org/10.1016/j.watres.2020.115901

Li, Y., Liu, J., Cao, Z., Lin, C. \& Yang, Z. (2010) Spatial distribution and health risk of heavy metals and polycyclic aromatic hydrocarbons (PAHs) in the water of the Luanhe River Basin, China. Environ Monit Assess, 163 (1-4), 1-13. https://doi.org/10.1007/s10661-009-0811-2

Lu, J., Zhang, C., Wu, J., Lin, Y., Zhang, Y., Yu, X. \& Zhang, Z. (2019) Pollution, sources, and ecologicalhealth risks of polycyclic aromatic hydrocarbons in coastal waters along coastline of China. Human and Ecological Risk Assessment: An International Journal, 26 (4), 968-985. https://doi.org/10.1080/10807039.2018.1548899

Maskaoui, K., Zhou, J. L., Hong, H. S. \& Zhang, Z. L. (2002) Contamination by polycyclic aromatic hydrocarbons in the Jiulong River Estuary and Western Xiamen Sea, China. Environmental Pollution, 118 (1), 109-122. https://doi.org/10.1016/S0269-7491(01)00208-1

Meng, Y., Liu, X., Lu, S., Zhang, T., Jin, B., Wang, Q., Tang, Z., Liu, Y., Guo, X., Zhou, J. \& Xi, B. (2019) A review on occurrence and risk of polycyclic aromatic hydrocarbons (PAHs) in lakes of China. Sci Total Environ, 651 (Pt 2), 2497-2506. https://doi.org/10.1016/j.scitotenv.2018.10.162

Mojiri, A., Zhou, J. L., Ohashi, A., Ozaki, N. \& Kindaichi, T. (2019) Comprehensive review of polycyclic aromatic hydrocarbons in water sources, their effects and treatments. Sci Total Environ, 696, 133971. https://doi.org/10.1016/j.scitotenv.2019.133971

Nadal, M., Schuhmacher, M. \& Domingo, J. L. (2004) Levels of PAHs in soil and vegetation samples from Tarragona County, Spain. Environ Pollut, 132 (1), 1-11. https://doi.org/10.1016/j.envpol.2004.04.003

Nascimento, R. A., de Almeida, M., Escobar, N. C. F., Ferreira, S. L. C., Mortatti, J. \& Queiroz, A. F. S. (2017) Sources and distribution of polycyclic aromatic hydrocarbons (PAHs) and organic matter in surface sediments of an estuary under petroleum activity influence, Todos os Santos Bay, Brazil. Mar Pollut Bull, 119 (2), 223-230. https://doi.org/10.1016/j.marpolbul.2017.03.069

Niu, L. \& van Gelder, P. (2020) Distribution and source assessment of polycyclic aromatic hydrocarbons levels from Lake IJssel (the Netherlands) and their responses to hydrology. Water Environ Res, 92 (8), 1214-1229. https://doi.org/10.1002/wer.1317 
Opere, W. M., John, M. \& Ombori, O. (2020) Occurrence of Enteric Viruses in Surface Water and the Relationship with Changes in Season and Physical Water Quality Dynamics. Adv Virol, 2020, 9062041. https://doi.org/10.1155/2020/9062041

Palm, A., Cousins, I., Gustafsson, O., Axelman, J., Grunder, K., Broman, D. \& Brorstrom-Lunden, E. (2004) Evaluation of sequentially-coupled POP fluxes estimated from simultaneous measurements in multiple compartments of an air-water-sediment system. Environ Pollut, 128 (1-2), 85-97. https://doi.org/10.1016/j.envpol.2003.08.023

Patrolecco, L., Ademollo, N., Capri, S., Pagnotta, R. \& Polesello, S. (2010) Occurrence of priority hazardous PAHs in water, suspended particulate matter, sediment and common eels (Anguilla anguilla) in the urban stretch of the River Tiber (Italy). Chemosphere, 81 (11), 1386-1392. https://doi.org/10.1016/j.chemosphere.2010.09.027

Pies, C., Hoffmann, B., Petrowsky, J., Yang, Y., Ternes, T. A. \& Hofmann, T. (2008) Characterization and source identification of polycyclic aromatic hydrocarbons (PAHs) in river bank soils. Chemosphere, 72 (10), 1594-1601. https://doi.org/10.1016/j.chemosphere.2008.04.021

Qiao, M., Wang, C., Huang, S., Wang, D. \& Wang, Z. (2006) Composition, sources, and potential toxicological significance of PAHs in the surface sediments of the Meiliang Bay, Taihu Lake, China. Environ Int, 32 (1), 28-33. https://doi.org/10.1016/j.envint.2005.04.005

Saeedi, M., Li, L. Y. \& Salmanzadeh, M. (2012) Heavy metals and polycyclic aromatic hydrocarbons: pollution and ecological risk assessment in street dust of Tehran. J Hazard Mater, 227-228, 917. https://doi.org/10.1016/j.jhazmat.2012.04.047

Sanches, S., Leitao, C., Penetra, A., Cardoso, V. V., Ferreira, E., Benoliel, M. J., Crespo, M. T. \& Pereira, V. J. (2011) Direct photolysis of polycyclic aromatic hydrocarbons in drinking water sources. $J$ Hazard Mater, 192 (3), 1458-1465. https://doi.org/10.1016/j.jhazmat.2011.06.065

Sarria-Villa, R., Ocampo-Duque, W., Paez, M. \& Schuhmacher, M. (2016) Presence of PAHs in water and sediments of the Colombian Cauca River during heavy rain episodes, and implications for $\begin{array}{lllll}\text { risk assessment. } & \text { Sci } & \text { Total Environ, } & \text { 540, }\end{array}$ https://doi.org/10.1016/j.scitotenv.2015.07.020

Seopela, M. P., McCrindle, R. I., Combrinck, S. \& Augustyn, W. (2020) Occurrence, distribution, spatiotemporal variability and source identification of n-alkanes and polycyclic aromatic hydrocarbons in water and sediment from Loskop dam, South Africa. Water Res, 186, 116350. https://doi.org/10.1016/j.watres.2020.116350

Shen, B., Wu, J., Zhan, S. \& Jin, M. (2021) Residues of organochlorine pesticides (OCPs) and polycyclic aromatic hydrocarbons (PAHs) in waters of the Ili-Balkhash Basin, arid Central Asia: Concentrations and risk assessment. Chemosphere, 273, 129705. https://doi.org/10.1016/j.chemosphere.2021.129705

Sun, C., Zhang, J., Ma, Q. \& Chen, Y. (2015) Human Health and Ecological Risk Assessment of 16 Polycyclic Aromatic Hydrocarbons in Drinking Source Water from a Large Mixed-Use Reservoir. Int $J$ Environ Res Public Health, 12 (11), 13956-13969. https://doi.org/10.3390/ijerph121113956

Sun, J. H., Wang, G. L., Chai, Y., Zhang, G., Li, J. \& Feng, J. (2009) Distribution of polycyclic aromatic hydrocarbons (PAHs) in Henan Reach of the Yellow River, Middle China. Ecotoxicol Environ Saf, 72 (5), 1614-1624. https://doi.org/10.1016/j.ecoenv.2008.05.010

Takane, Y. \& Hwang, H. (2005) On a test of dimensionality in redundancy analysis. Psychometrika, 70 (2), 271-281. https://doi.org/10.1007/s11336-003-1089-x 
Tobiszewski, M. \& Namiesnik, J. (2012) PAH diagnostic ratios for the identification of pollution emission sources. Environ Pollut, 162, 110-119. https://doi.org/10.1016/j.envpol.2011.10.025

Yim, U. H., Hong, S. H. \& Shim, W. J. (2007) Distribution and characteristics of PAHs in sediments from the marine environment of Korea. Chemosphere, 68 (1), 85-92. https://doi.org/10.1016/j.chemosphere.2006.12.032

Yu, H., Liu, Y., Han, C., Fang, H., Weng, J., Shu, X., Pan, Y. \& Ma, L. (2021) Polycyclic aromatic hydrocarbons in surface waters from the seven main river basins of China: Spatial distribution, source apportionment, and potential risk assessment. Sci Total Environ, 752, 141764. https://doi.org/10.1016/j.scitotenv.2020.141764

Yu, Y., Xu, J., Wang, P., Sun, H. \& Dai, S. (2009) Sediment-porewater partition of polycyclic aromatic hydrocarbons (PAHs) from Lanzhou Reach of Yellow River, China. J Hazard Mater, 165 (1-3), 494-500. https://doi.org/10.1016/j.jhazmat.2008.10.042

Yuan, K., Wang, X., Lin, L., Zou, S., Li, Y., Yang, Q. \& Luan, T. (2015) Characterizing the parent and alkyl polycyclic aromatic hydrocarbons in the Pearl River Estuary, Daya Bay and northern South China Sea: influence of riverine input. Environ Pollut, 199, 66-72. https://doi.org/10.1016/j.envpol.2015.01.017

Yunker, M. B., Macdonald, R. W., Vingarzan, R., Mitchell, R. H., Goyette, D. \& Sylvestre, S. (2002) PAHs in the Fraser River basin: a critical appraisal of PAH ratios as indicators of PAH source and composition. Organic Geochemistry, 33 (4), 489-515. https://doi.org/10.1016/S01466380(02)00002-5

Zhang, H. B., Luo, Y. M., Wong, M. H., Zhao, Q. G. \& Zhang, G. L. (2006) Distributions and concentrations of PAHs in Hong Kong soils. Environ Pollut, 141 (1), 107-114. https://doi.org/10.1016/j.envpol.2005.08.031

Zhang, J., Liu, G., Wang, R. \& Huang, H. (2017) Polycyclic aromatic hydrocarbons in the water-SPMsediment system from the middle reaches of Huai River, China: Distribution, partitioning, origin tracing and ecological risk assessment. Environ Pollut, 230, 61-71. https://doi.org/10.1016/j.envpol.2017.06.012

Zhang, Y., Lu, Y., Xu, J., Yu, T. \& Zhao, W. (2011) Spatial distribution of polycyclic aromatic hydrocarbons from Lake Taihu, China. Bull Environ Contam Toxicol, 87 (1), 80-85. https://doi.org/10.1007/s00128-011-0292-1

Zhao, S. M., Wang, B., Wang, D. W., Li, X. M., Huang, B., Hu, P., Zhang, L. W. \& Pan, X. J. (2014) Environmental Behavior of PAHs in Dianchi Lake Distributions, Sources and Risk Assessment of Polycyclic Aromatic Hydrocarbons in Surface Sediments from Dianchi Lake,China. International Journal of Environmental Research, 8 (2), 317-328. https://dx.doi.org/10.22059/IJER.2014.722

Zheng, T., Ran, Y. \& Chen, L. (2013) Polycyclic aromatic hydrocarbons (PAHs) in rural soils of Dongjiang River Basin: occurrence, source apportionment, and potential human health risk. Journal of Soils and Sediments, 14 (1), 110-120. https://doi.org/10.1007/s11368-013-0753-8 


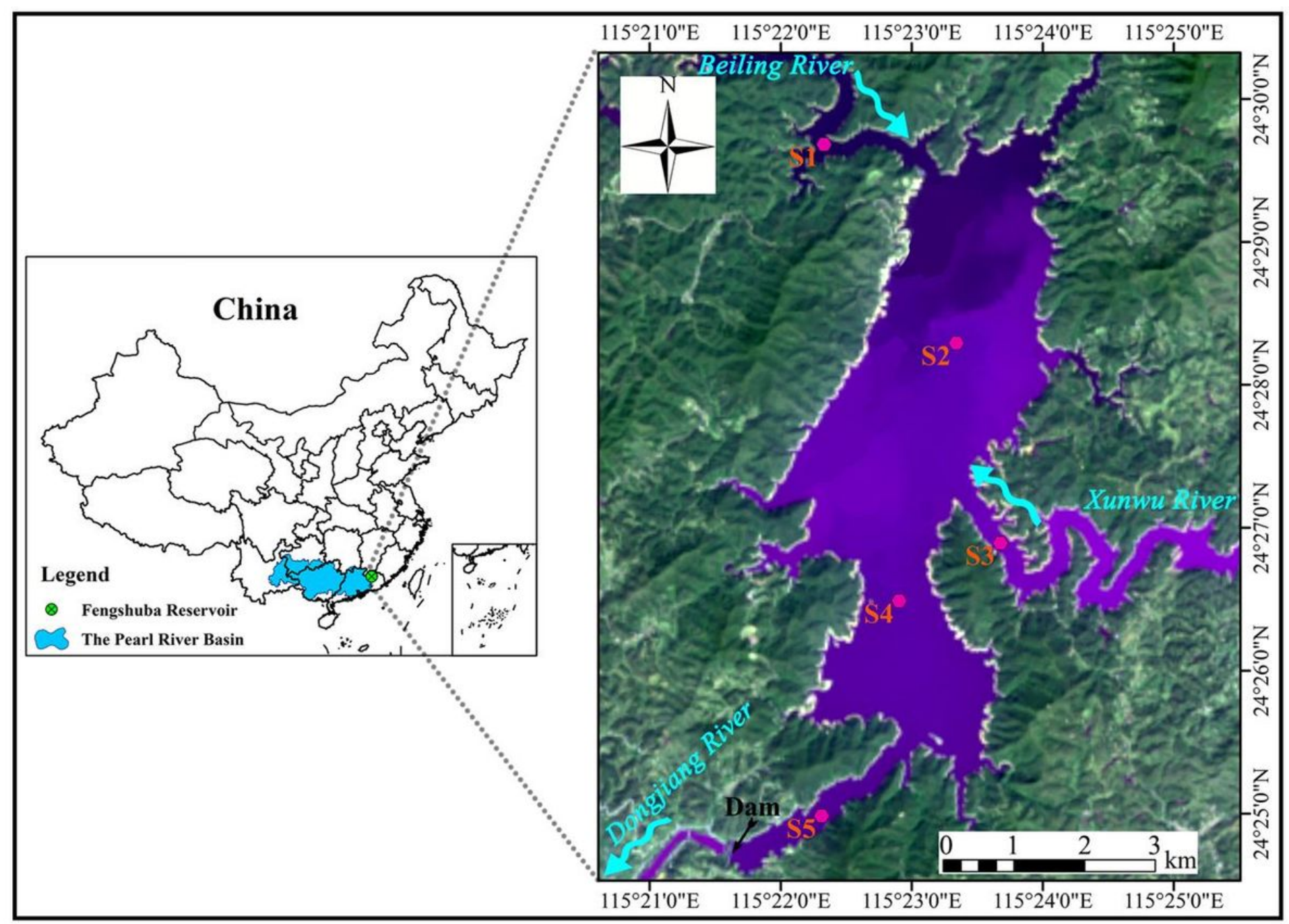

\section{Figure 1}

Map showing the location of Fengshuba Reservoir and sampling stations. S1 (northwest inlet of reservoir); S2 (upstream of reservoir); S3 (southeast inlet of reservoir); S4 (midstream of reservoir); S5 (downstream of reservoir). Note: The designations employed and the presentation of the material on this map do not imply the expression of any opinion whatsoever on the part of Research Square concerning the legal status of any country, territory, city or area or of its authorities, or concerning the delimitation of its frontiers or boundaries. This map has been provided by the authors. 

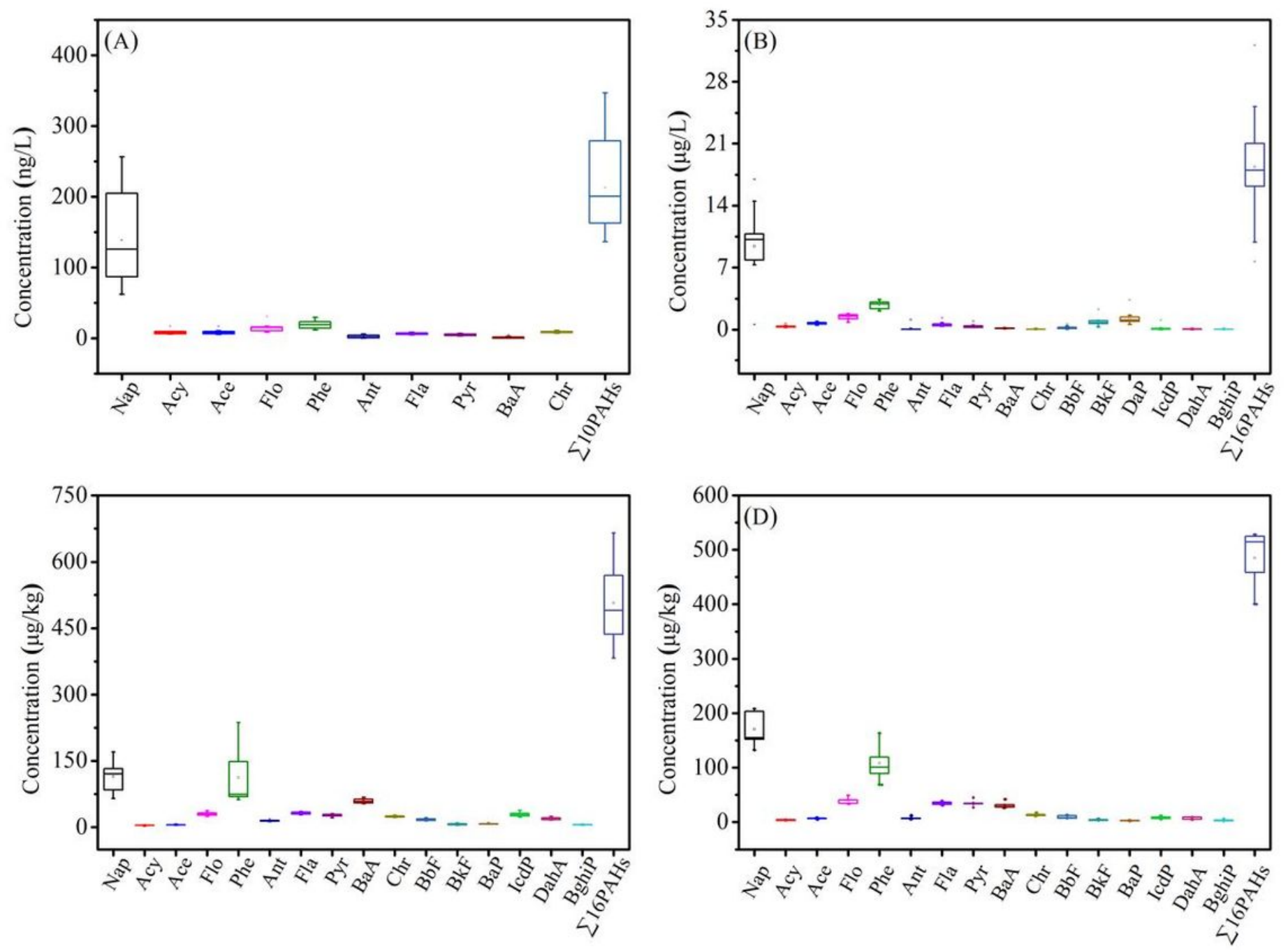

Figure 2

Concentrations of the PAHs in the waters (A), porewaters (B), sediments (C), and soils (D) of Fengshuba Reservoir. 

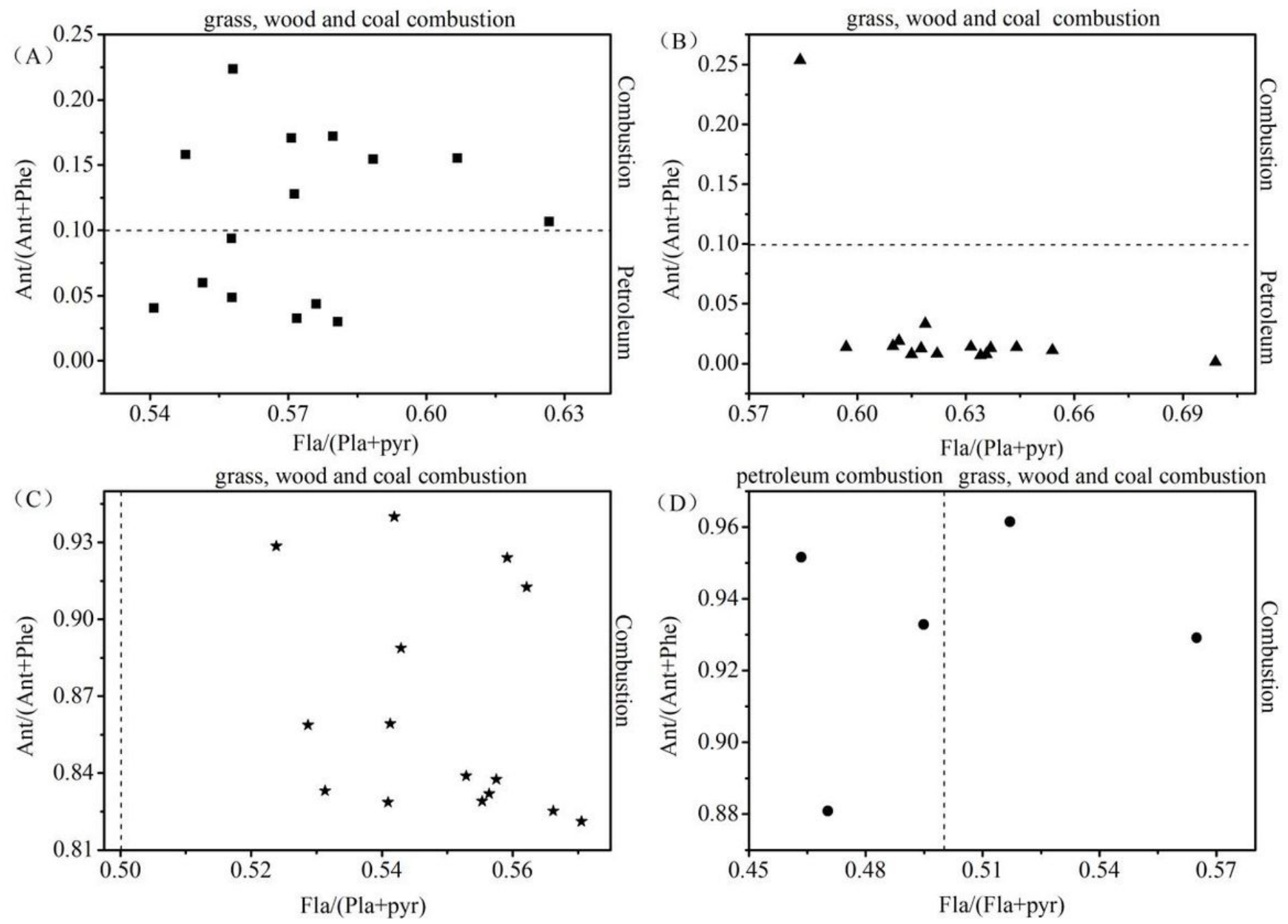

Figure 3

Plots of PAH isomer ratios for the identification of PAH sources: $\mathrm{Fla} /(\mathrm{Fla}+\mathrm{Pyr}) \mathrm{vs}$. Ant/(Ant + Phe) in water samples (A), porewater samples (B), sediments samples (C), and soil samples (D). 

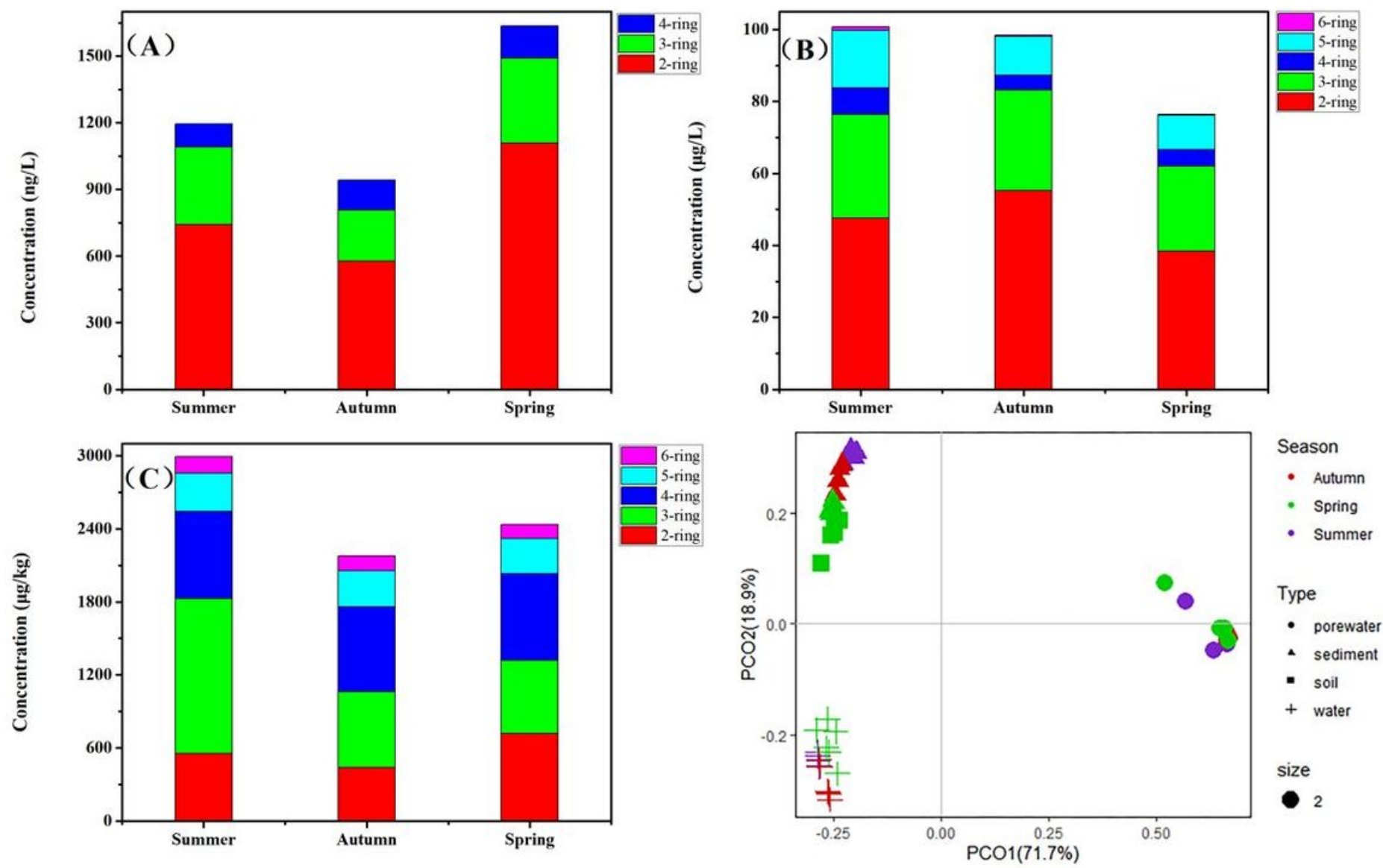

Figure 4

Concentrations of the PAHs in the waters (A), porewaters (B), and sediments (C) with the seasons. Compositions of the PAHs among the environmental compartments using the PCoA based on the BrayCurtis dissimilarity matrices (D). Error bars represent standard error of the mean. 


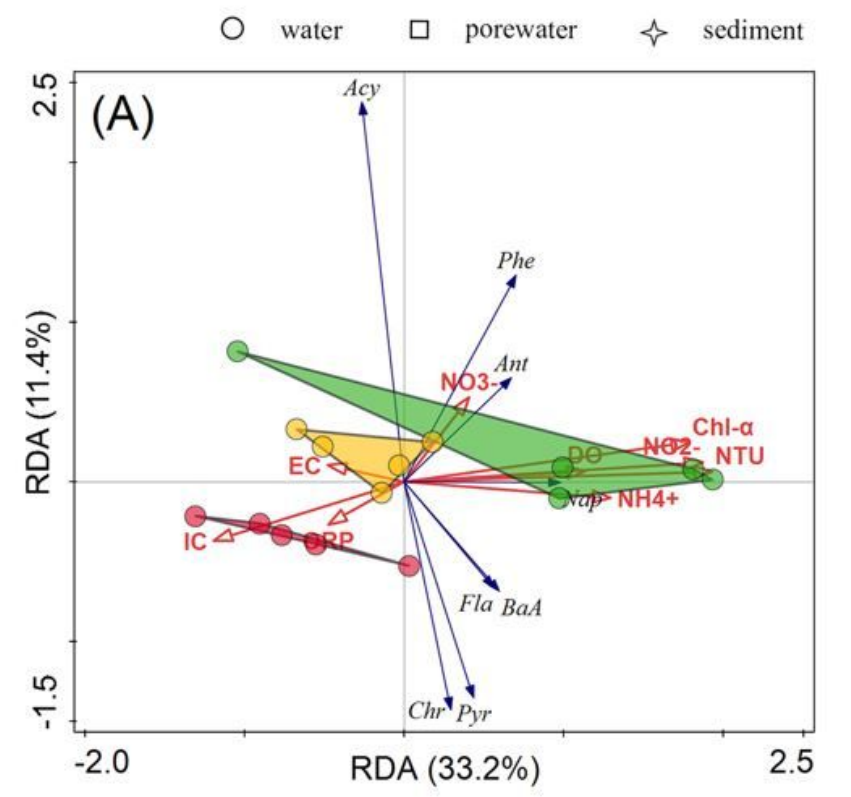

$\triangle \quad$ soil
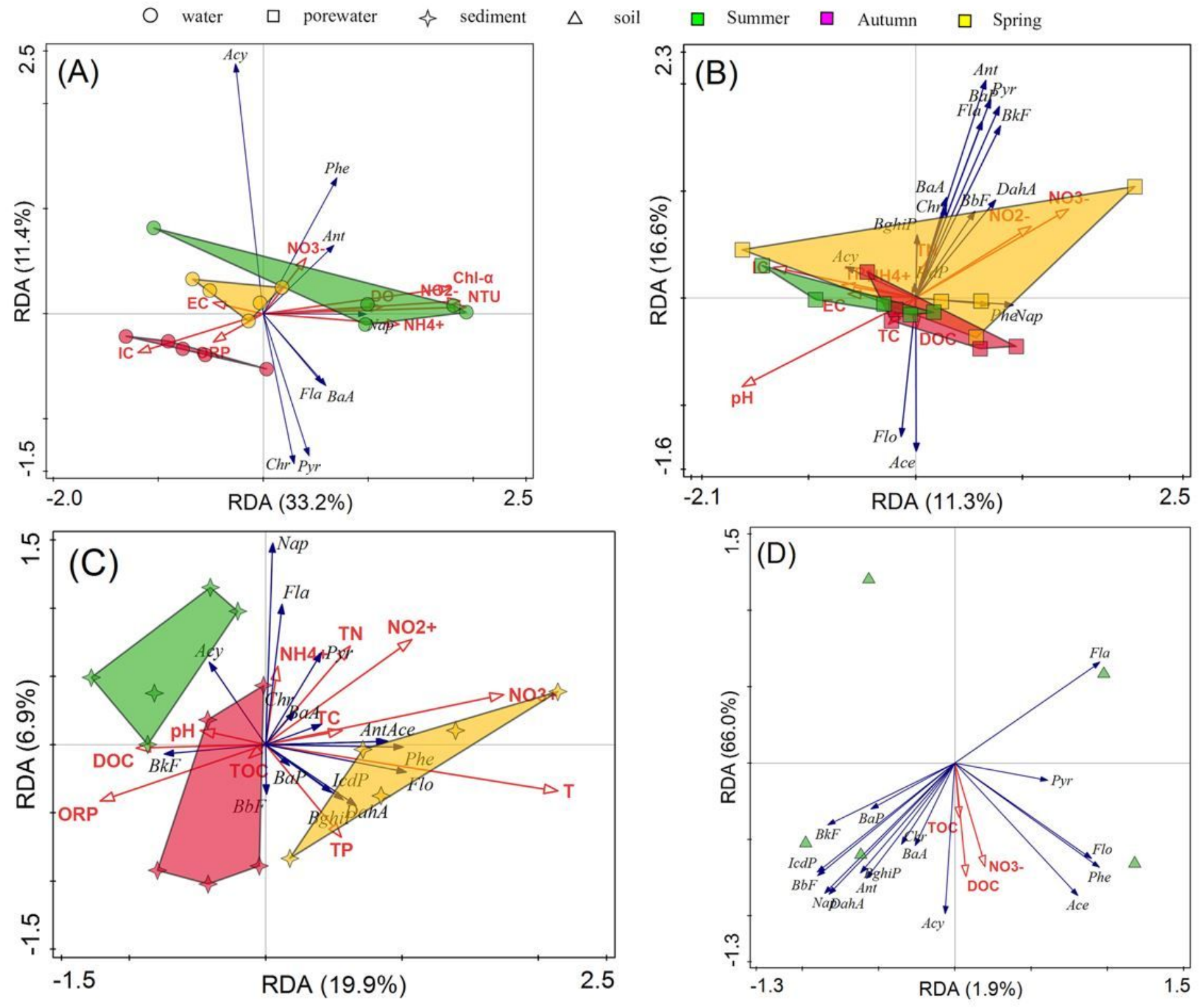

Figure 5

RDA of the PAHs concentrations and environmental concentrations in the waters (A), porewaters (B), sediments (C), and soils (D) of Fengshuba Reservoir. 

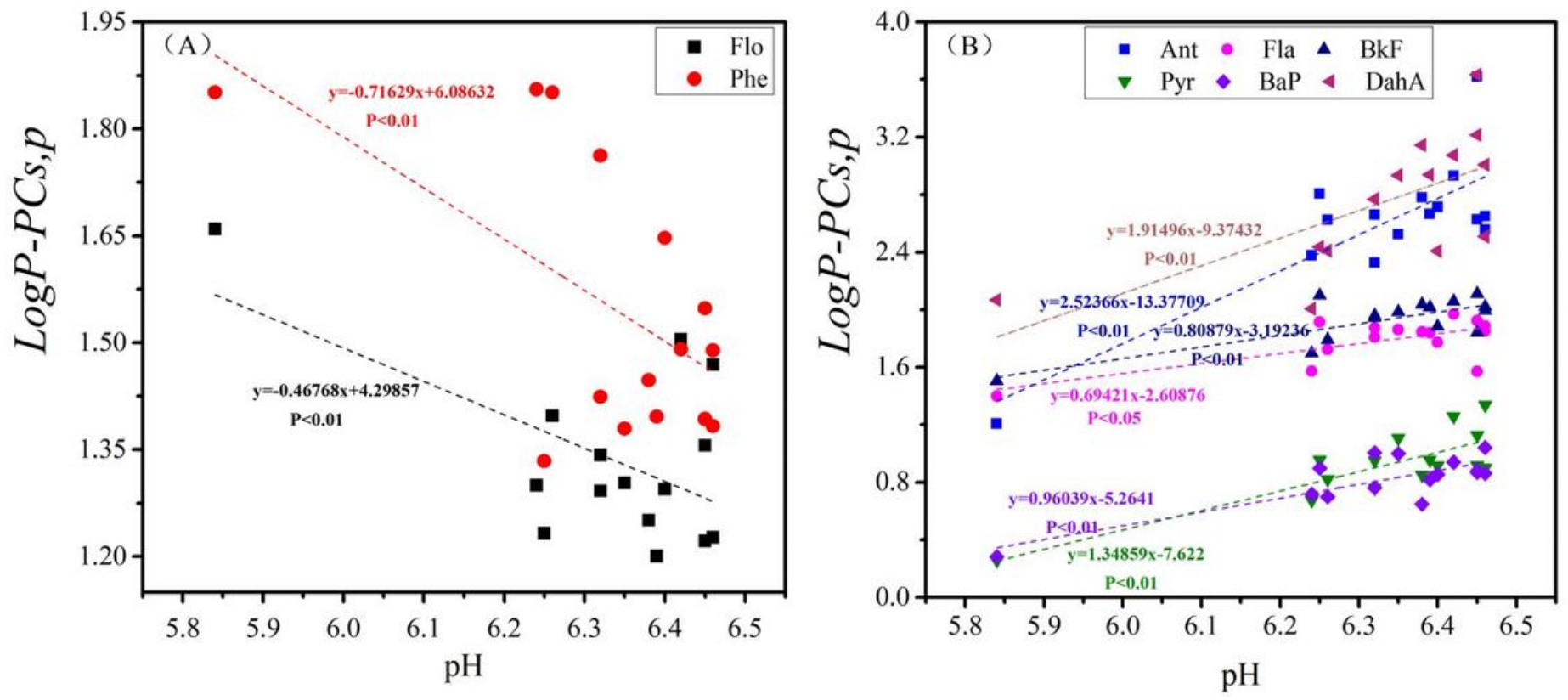

Figure 6

Linear correlation analysis of the Log P-PCs, w plotted against the $\mathrm{pH}$ level of in porewater phase. 
(A)
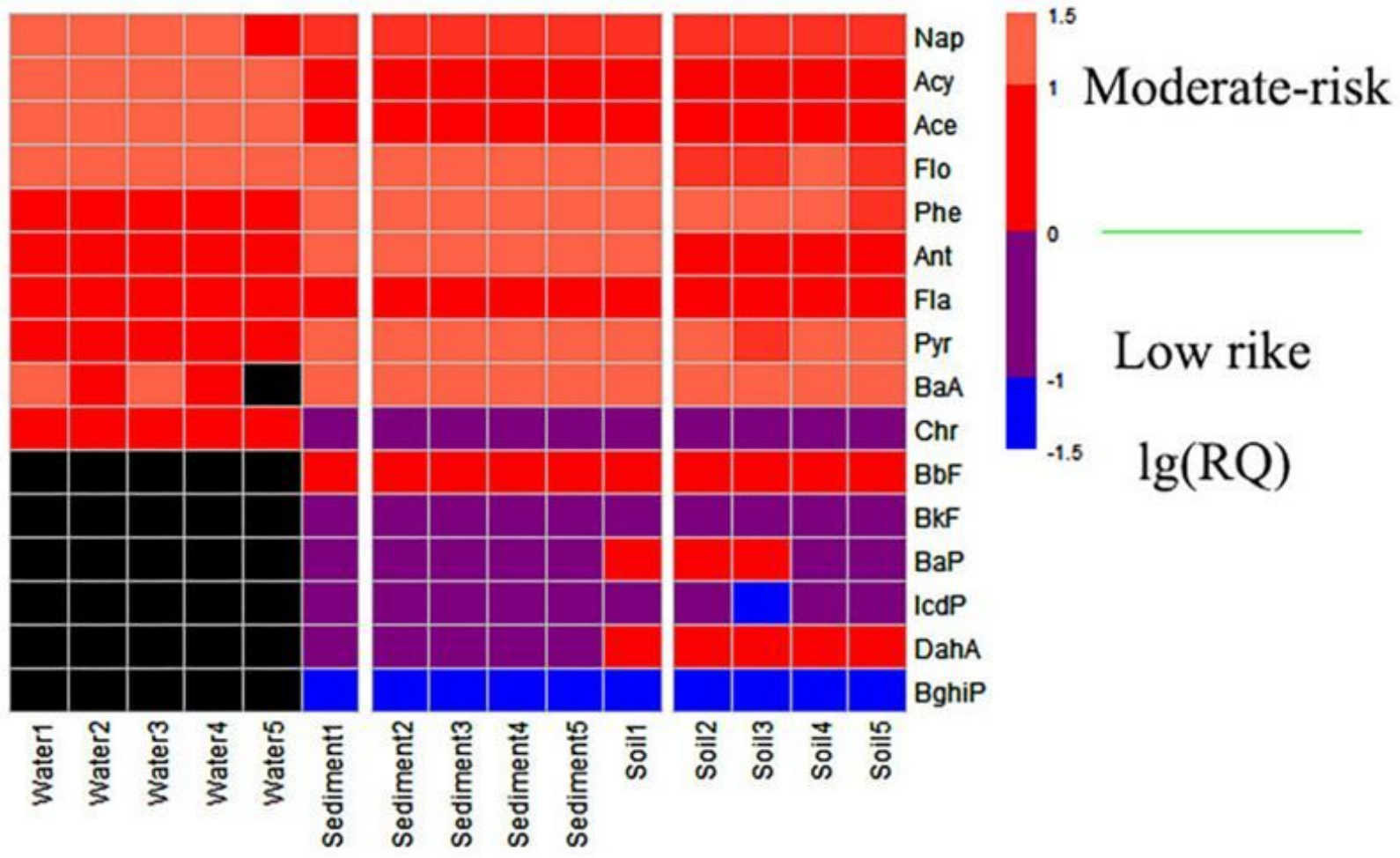

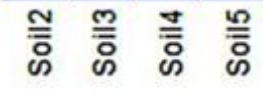
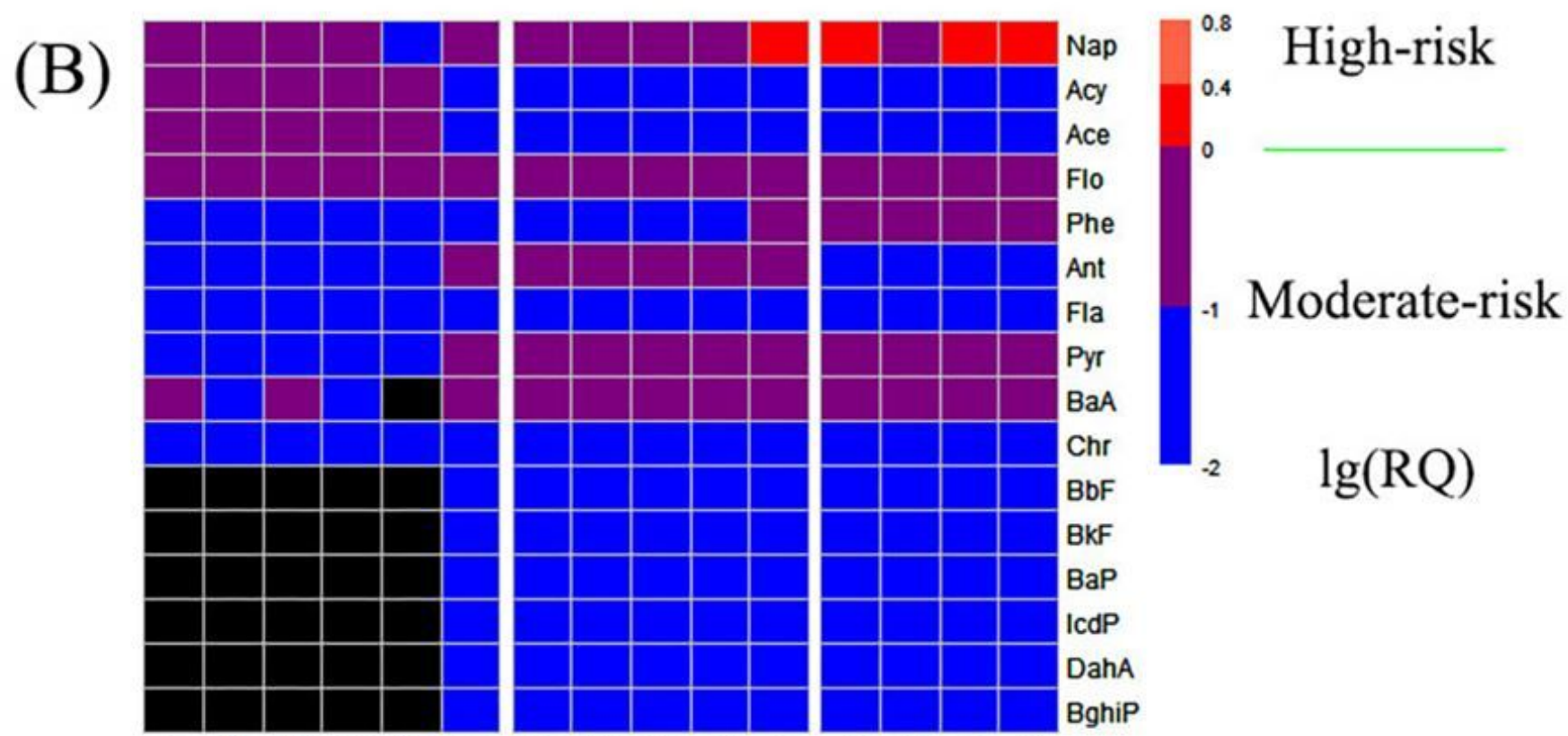

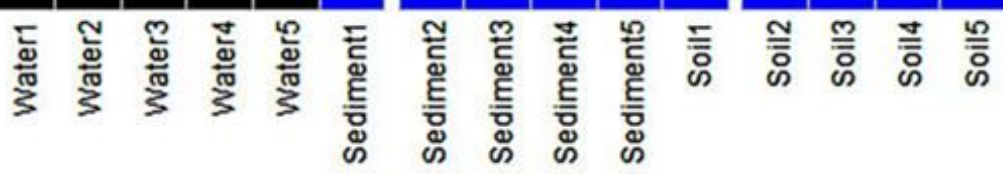

Figure 7

Calculated risk quotient (RQ) for the detected PAHs in the water, sediment, soil samples. Bottom right shows the color band indicator of the level of ecological risk based on a log scale. Black boxes indicate no ecological risks due to the corresponding PAHs undetected.

\section{Supplementary Files}


This is a list of supplementary files associated with this preprint. Click to download.

- Supportinginformation.docx 